\title{
Review Article \\ Clinical Trials in Cardiac Arrest and Subarachnoid Hemorrhage: Lessons from the Past and Ideas for the Future
}

\begin{abstract}
Jennifer A. Frontera
Cleveland Clinic Foundation, Neurological Institute, Cerebrovascular Center, Cleveland Clinic, 9500 Euclid Avenue S80, Cleveland, $\mathrm{OH} 44195$, USA
\end{abstract}

Correspondence should be addressed to Jennifer A. Frontera; frontej@ccf.org

Received 17 December 2012; Accepted 29 January 2013

Academic Editor: R. Loch Macdonald

Copyright (C) 2013 Jennifer A. Frontera. This is an open access article distributed under the Creative Commons Attribution License, which permits unrestricted use, distribution, and reproduction in any medium, provided the original work is properly cited.

\begin{abstract}
Introduction. Elevated intracranial pressure that occurs at the time of cerebral aneurysm rupture can lead to inadequate cerebral blood flow, which may mimic the brain injury cascade that occurs after cardiac arrest. Insights from clinical trials in cardiac arrest may provide direction for future early brain injury research after subarachnoid hemorrhage (SAH). Methods. A search of PubMed from 1980 to 2012 and clinicaltrials.gov was conducted to identify published and ongoing randomized clinical trials in aneurysmal SAH and cardiac arrest patients. Only English, adult, human studies with primary or secondary mortality or neurological outcomes were included. Results. A total of 142 trials ( $82 \mathrm{SAH}, 60$ cardiac arrest) met the review criteria (103 published, 39 ongoing). The majority of both published and ongoing SAH trials focus on delayed secondary insults after SAH (70\%), while $100 \%$ of cardiac arrest trials tested interventions within the first few hours of ictus. No SAH trials addressing treatment of early brain injury were identified. Twenty-nine percent of SAH and 13\% of cardiac arrest trials showed outcome benefit, though there is no overlap mechanistically. Conclusions. Clinical trials in SAH assessing acute brain injury are warranted and successful interventions identified by the cardiac arrest literature may be reasonable targets of the study.
\end{abstract}

\section{Introduction}

For decades, research efforts in subarachnoid hemorrhage (SAH) have focused on vasospasm and delayed ischemic neurological deficits. However, brain injury at the time of aneurysm rupture is a significant predictor of functional outcome. Indeed, poor admission neurological status (HuntHess or World Federation of Neurological Surgeons Score), which reflects acute brain injury, is a larger contributor to death or severe disability than delayed cerebral ischemia $[1,2]$. However, the mechanism of early brain injury after aneurysm rupture remains elusive and no current therapies are available.

One possible mechanism of acute injury was described in a small case series of 6 patients with observed recurrent aneurysm rupture either during transcranial Doppler (TCD) or during craniotomy with open skull but intact dura. The investigators report a spike in intracranial pressure (ICP) that developed over 1 minute and then declined over several minutes. This abrupt increase in ICP approached levels near mean arterial pressure and led to a concomitant drop in cerebral blood flow resulting in circulatory arrest, as documented by TCD [61]. This study examined aneurysm rebleeding and does not provide direct evidence that intracranial circulatory arrest occurs with de novo aneurysm rupture. However, inadequate cerebral blood flow is frequently evidenced clinically by the transient loss of consciousness that occurs at SAH ictus. This mechanism of global transient circulatory arrest has been described in animal models of SAH at the time of initial hemorrhage $[62,63]$ and mimics the anoxic/hypoxic ischemic mechanism incurred by cardiac arrest.

In this paper, published and ongoing clinical trials in cardiac arrest are compared to those in aneurysmal SAH to identify overlapping or complementary approaches to treatment as well as new avenues for potential research.

\section{Methods}

A search of PubMed was conducted in 11/2012 to identify randomized, controlled trials of aneurysmal SAH and cardiac arrest. Only human studies of adults ( $\geq 18$ years of age), which 


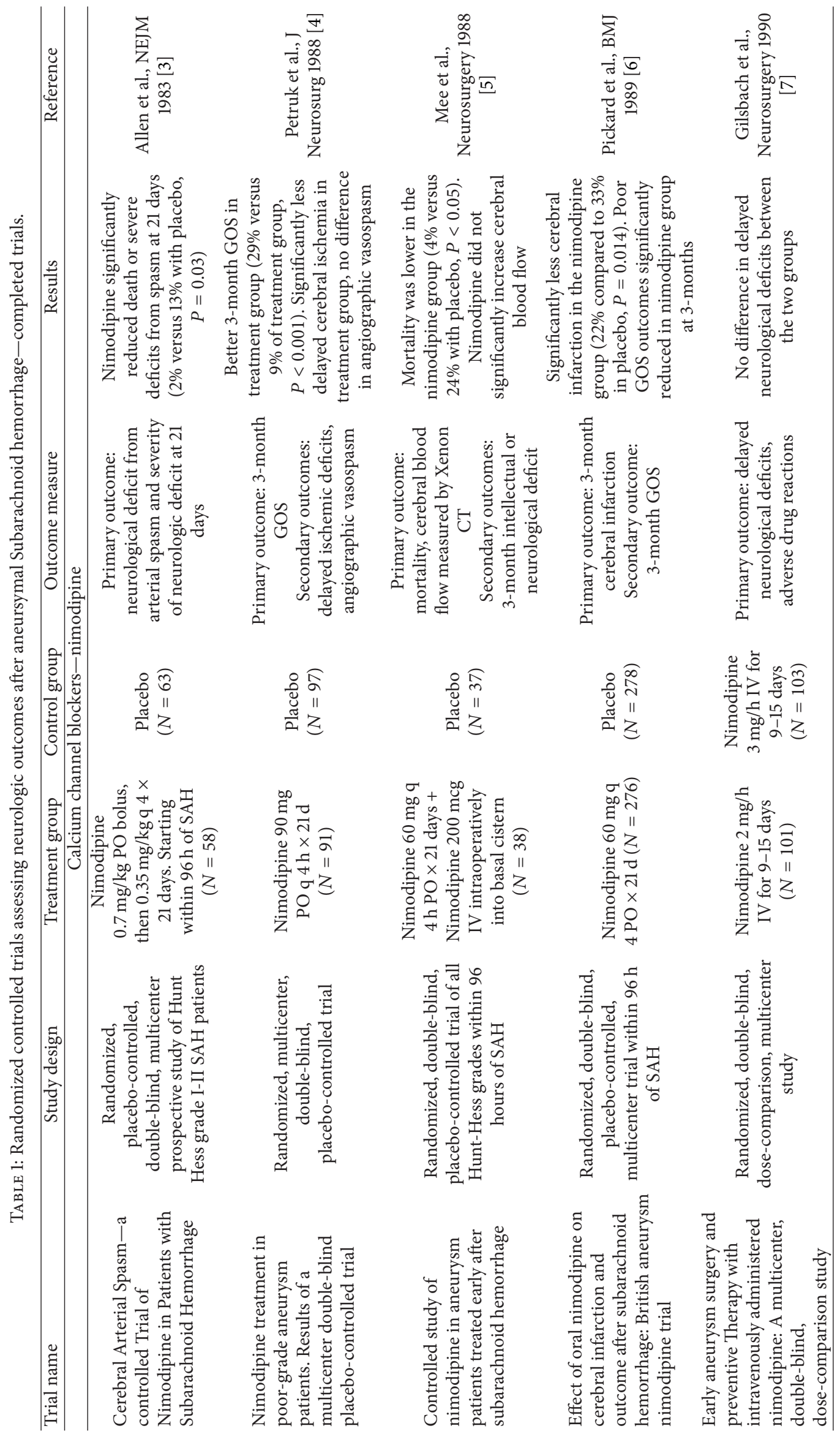




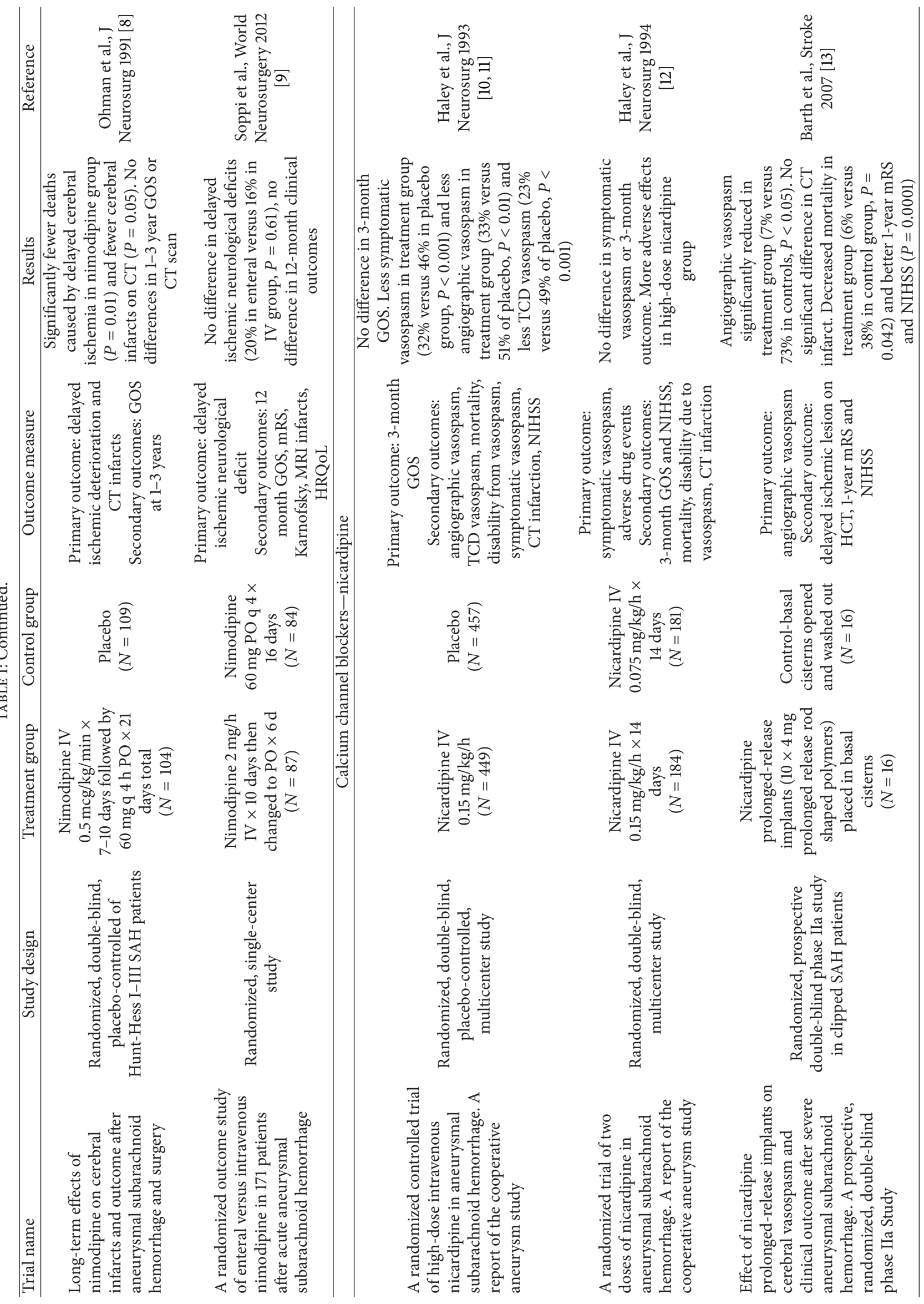




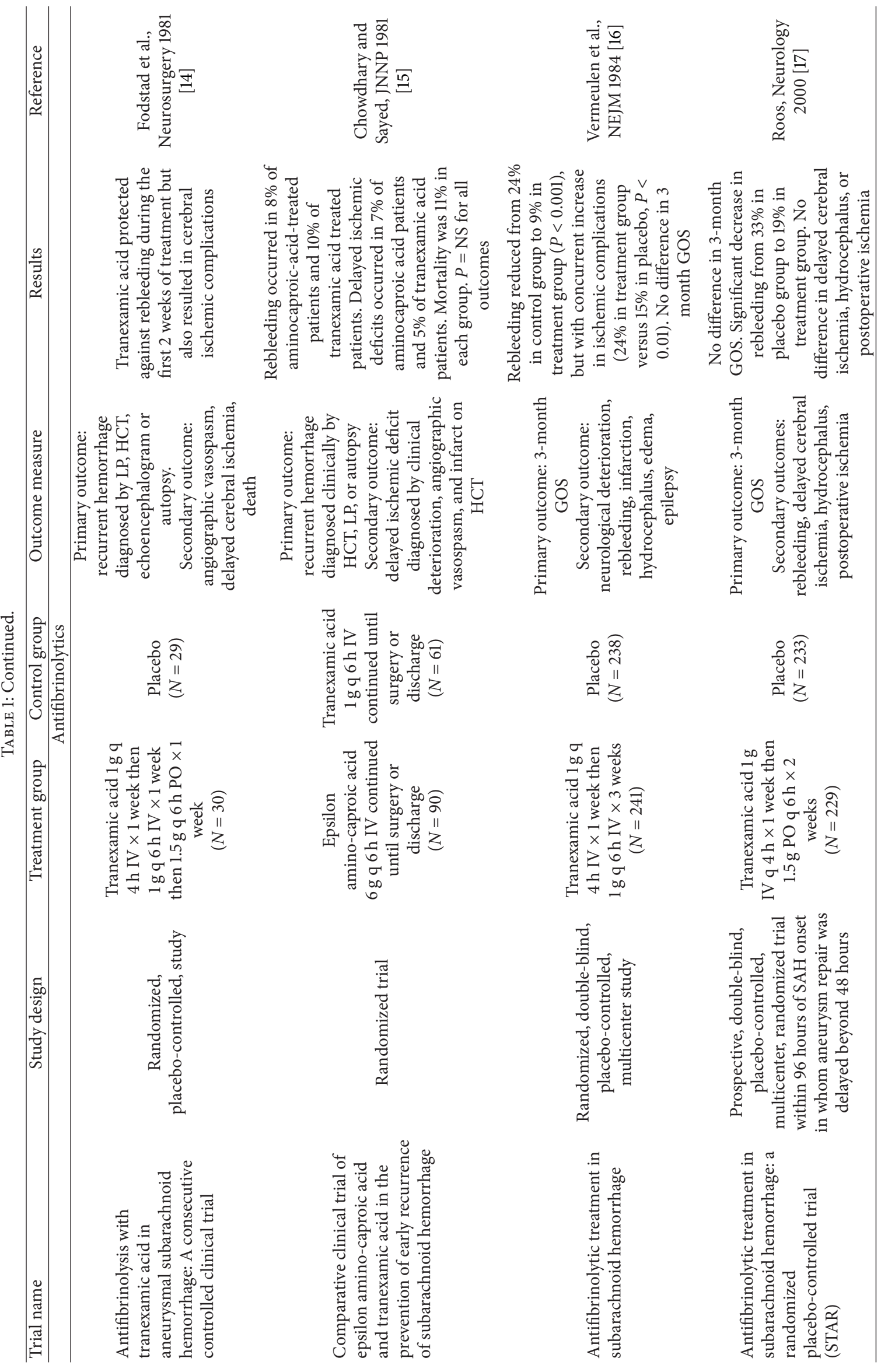




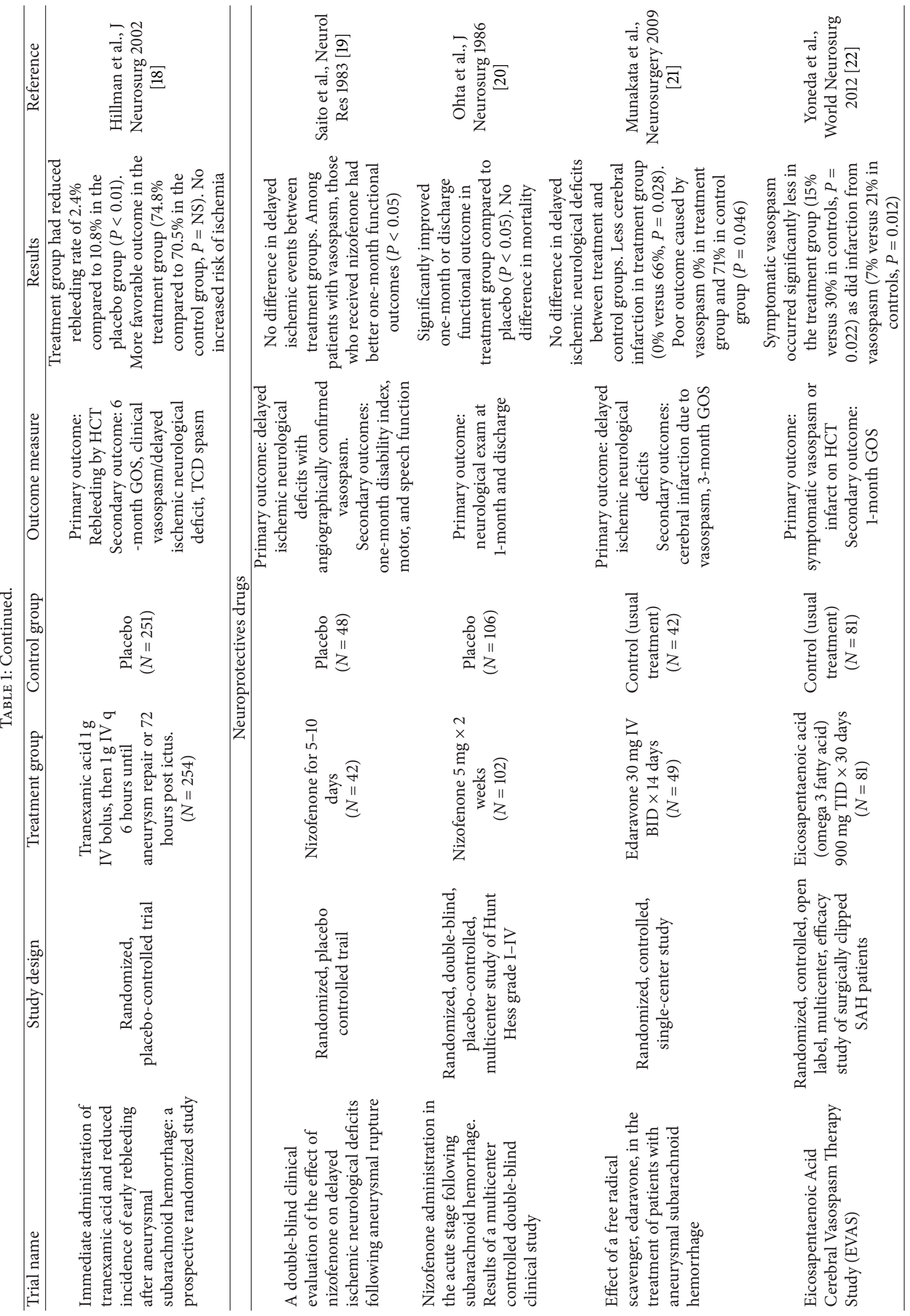




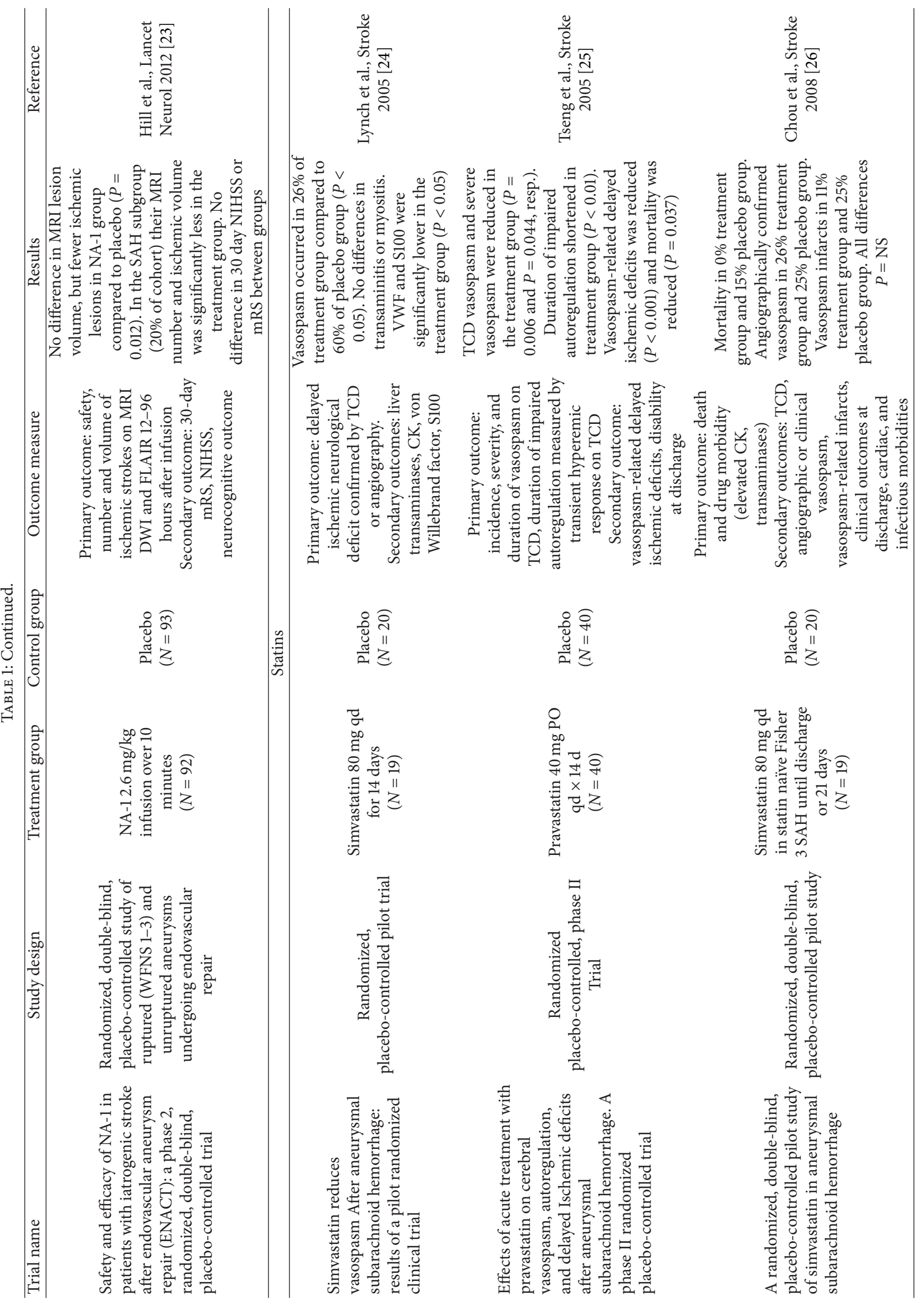




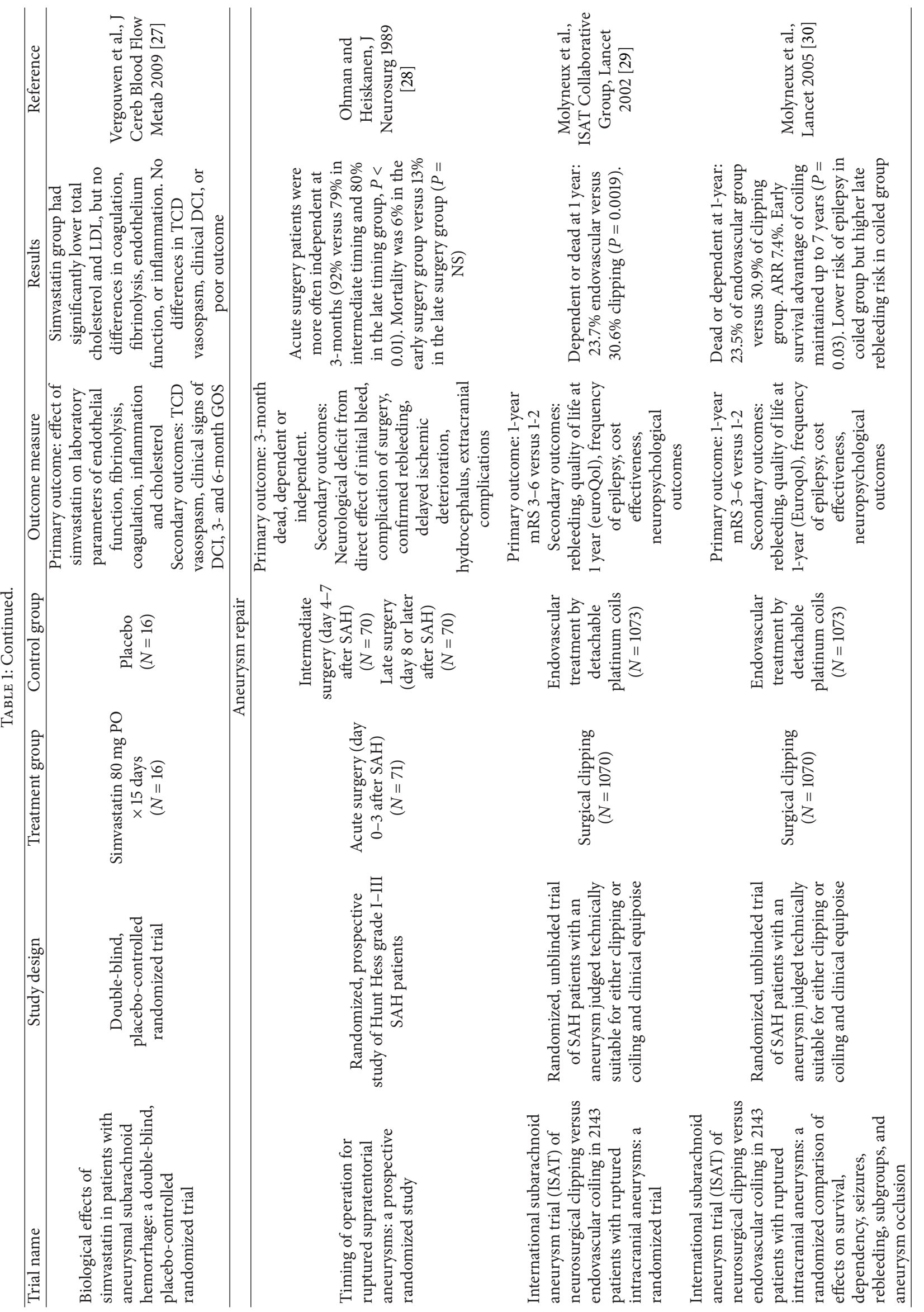




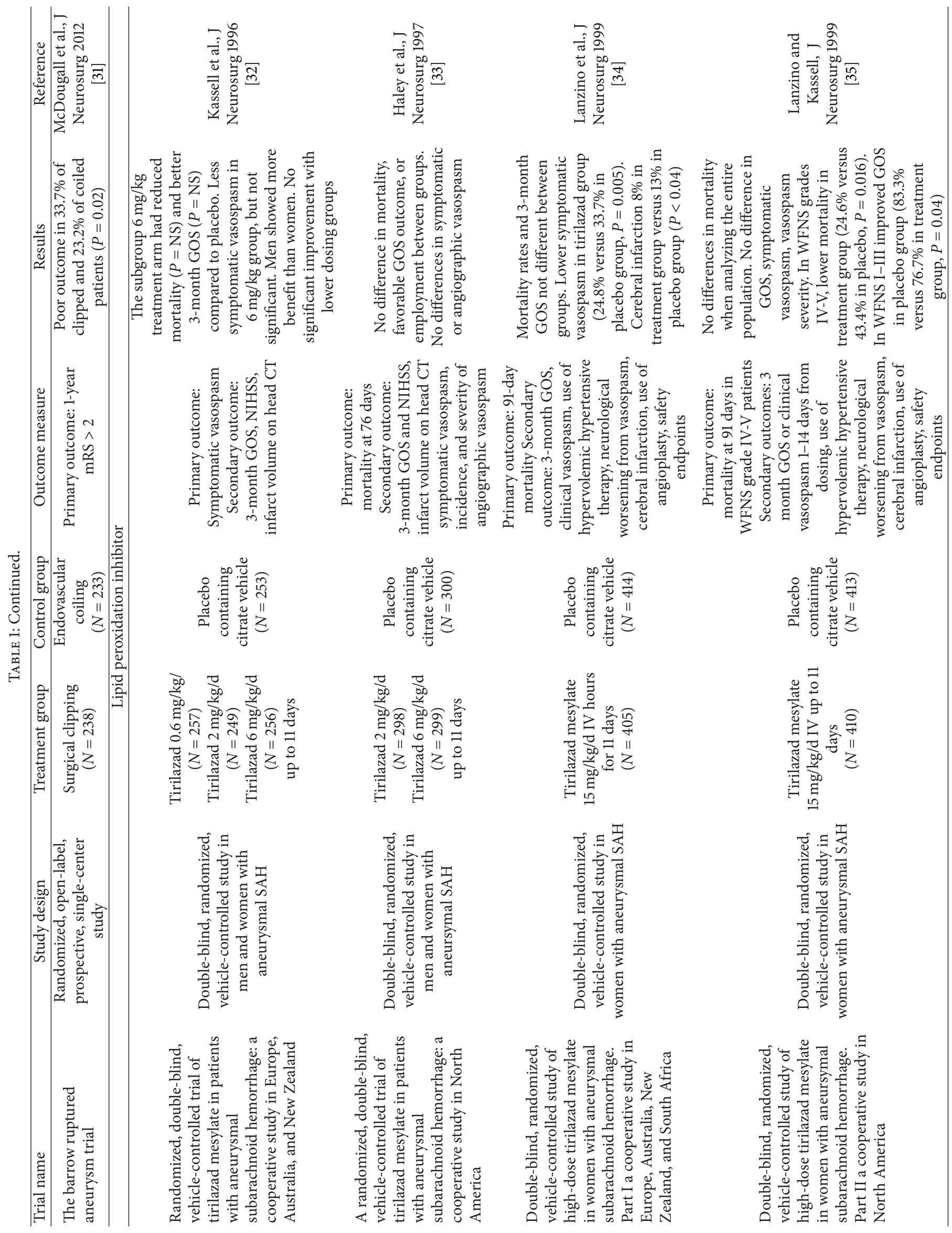




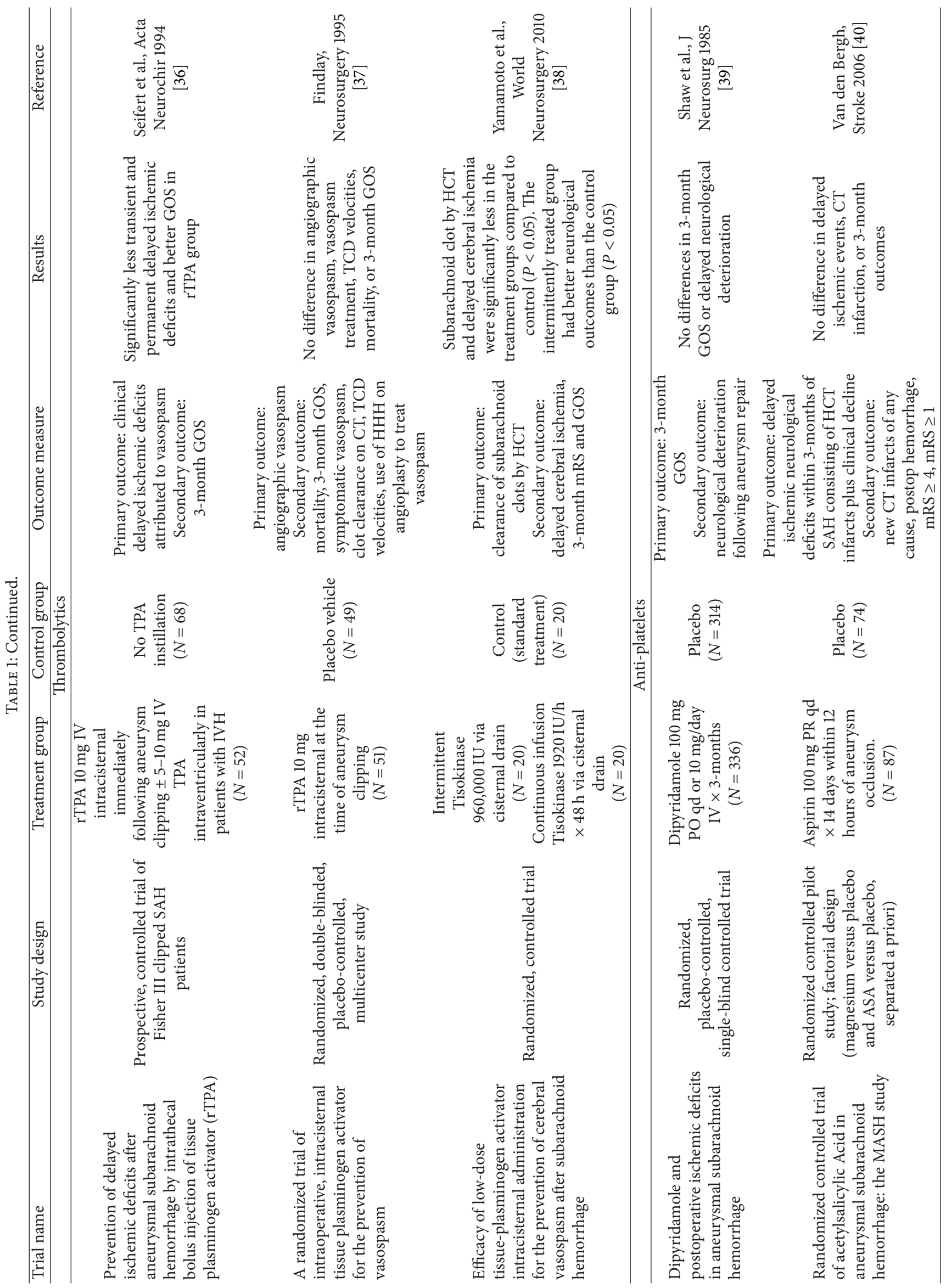




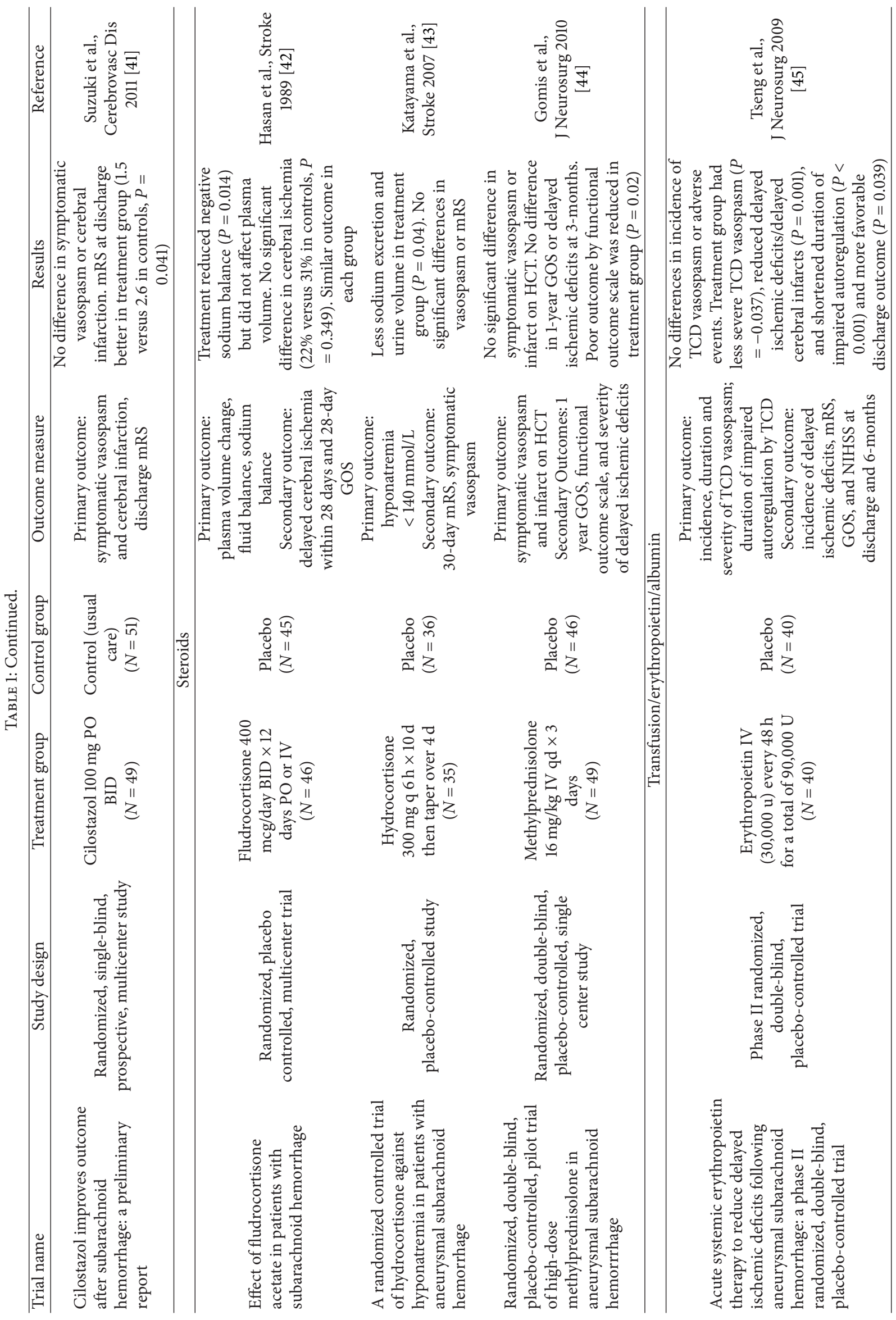




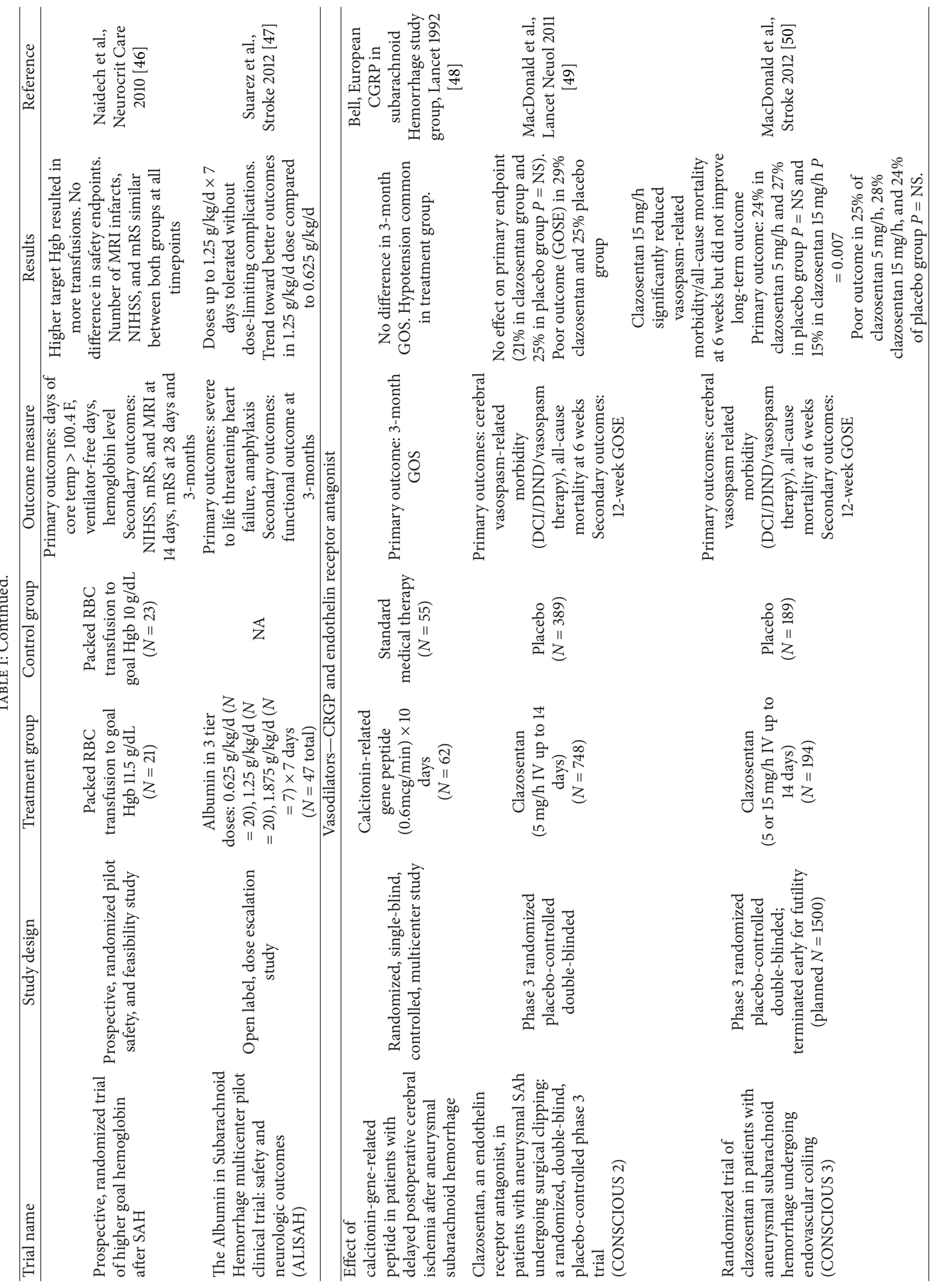




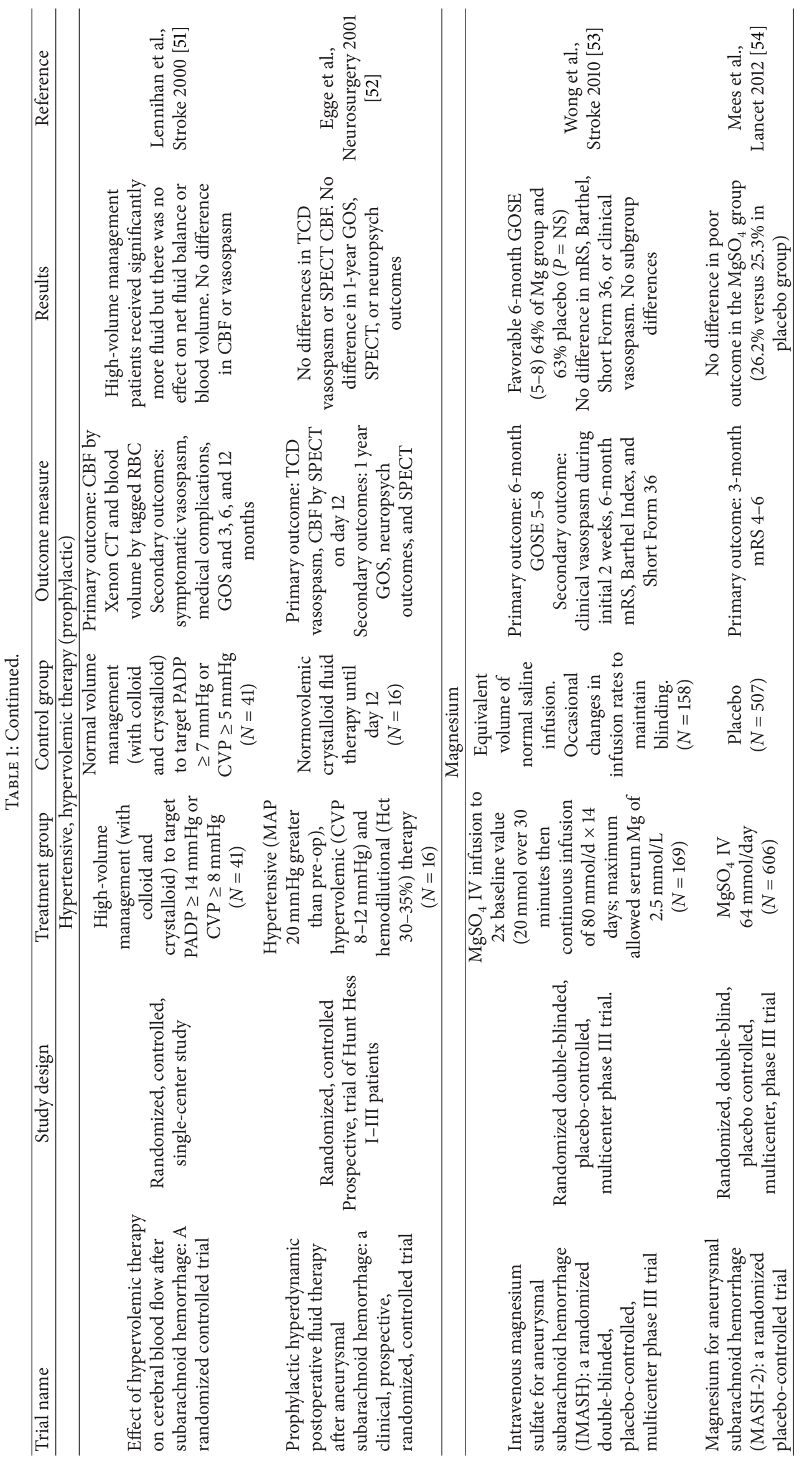



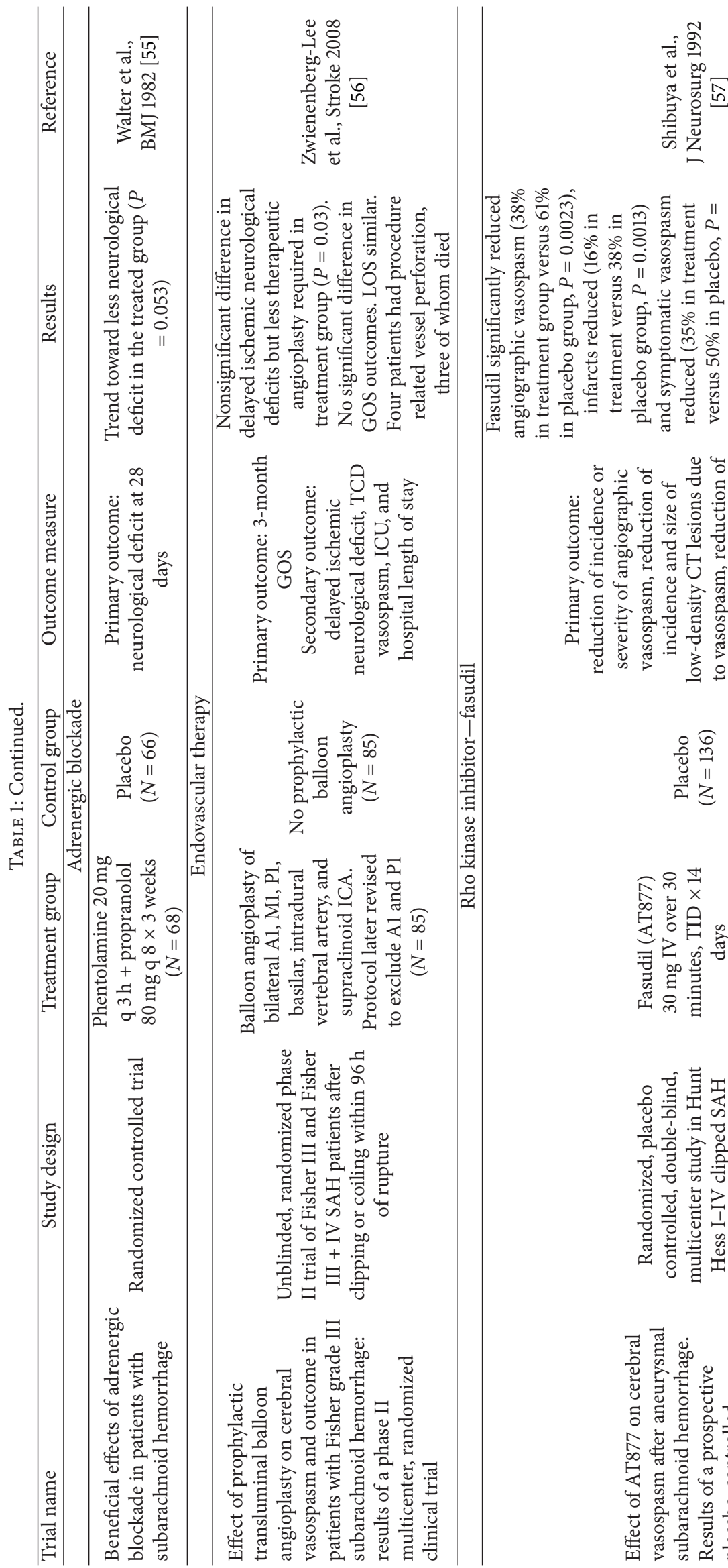

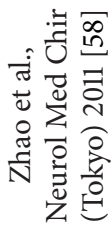

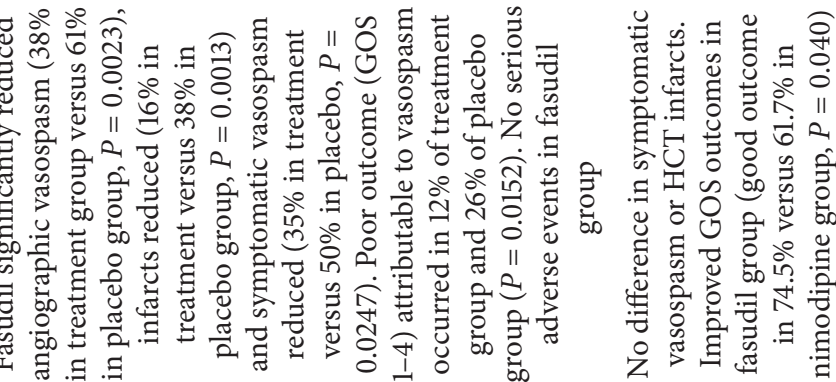
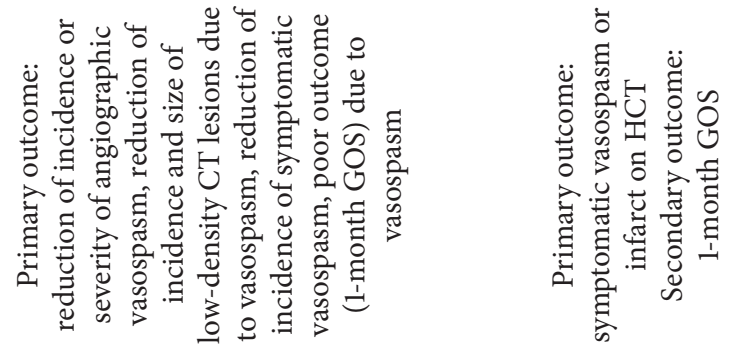

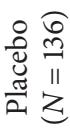

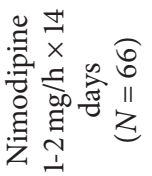
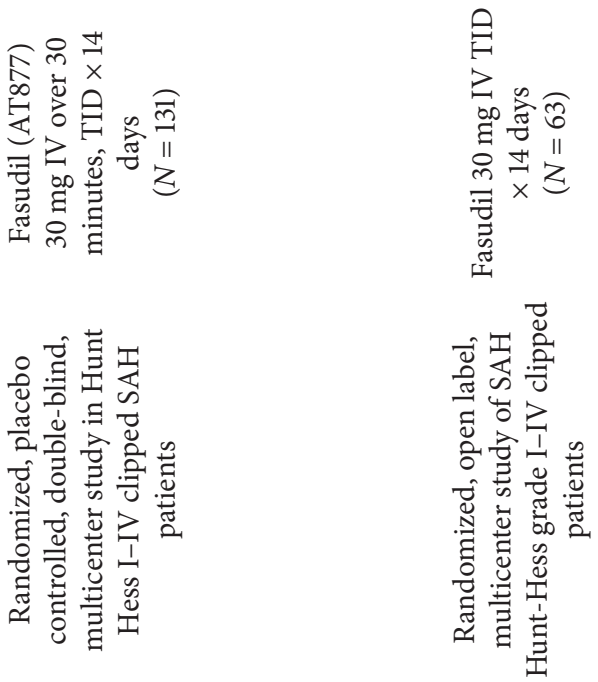

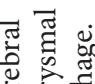

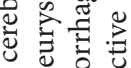

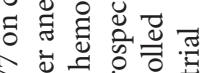

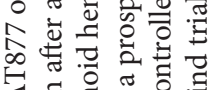

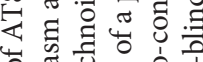

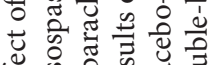

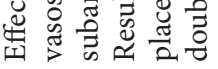

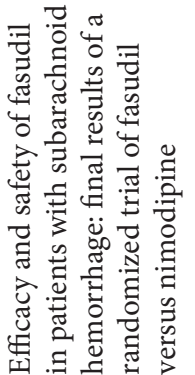




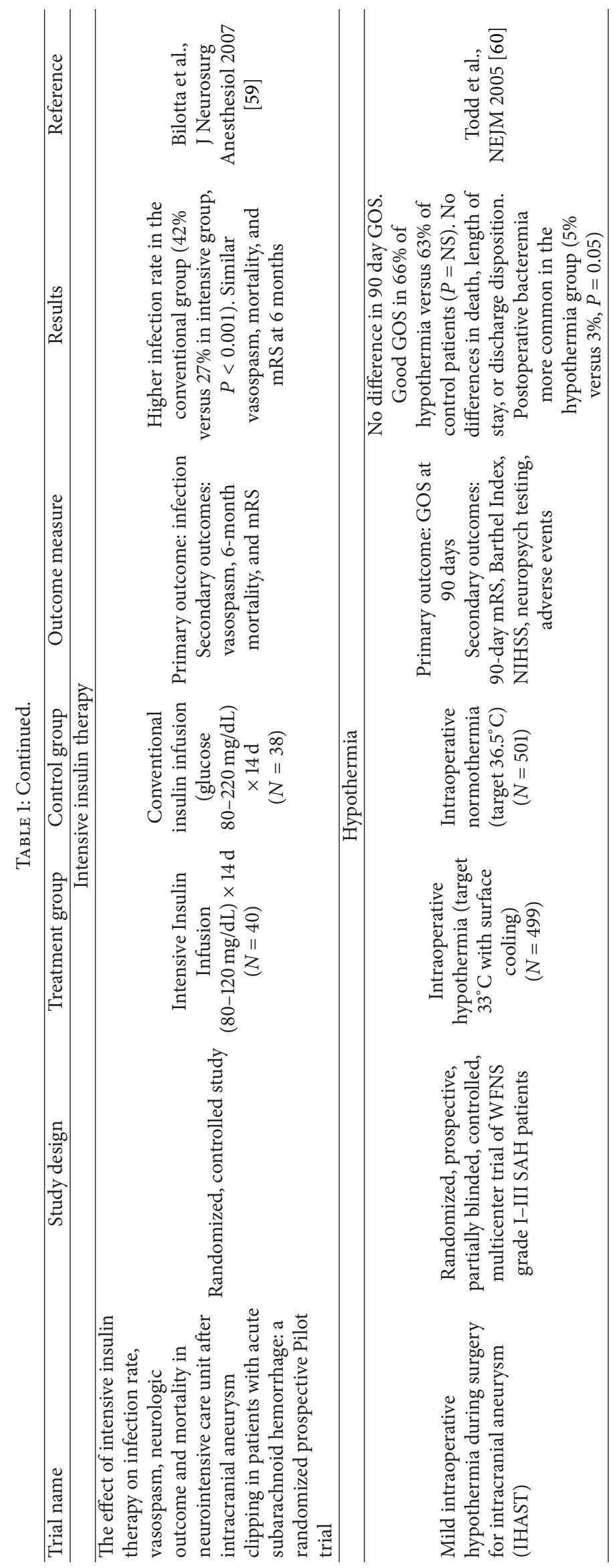




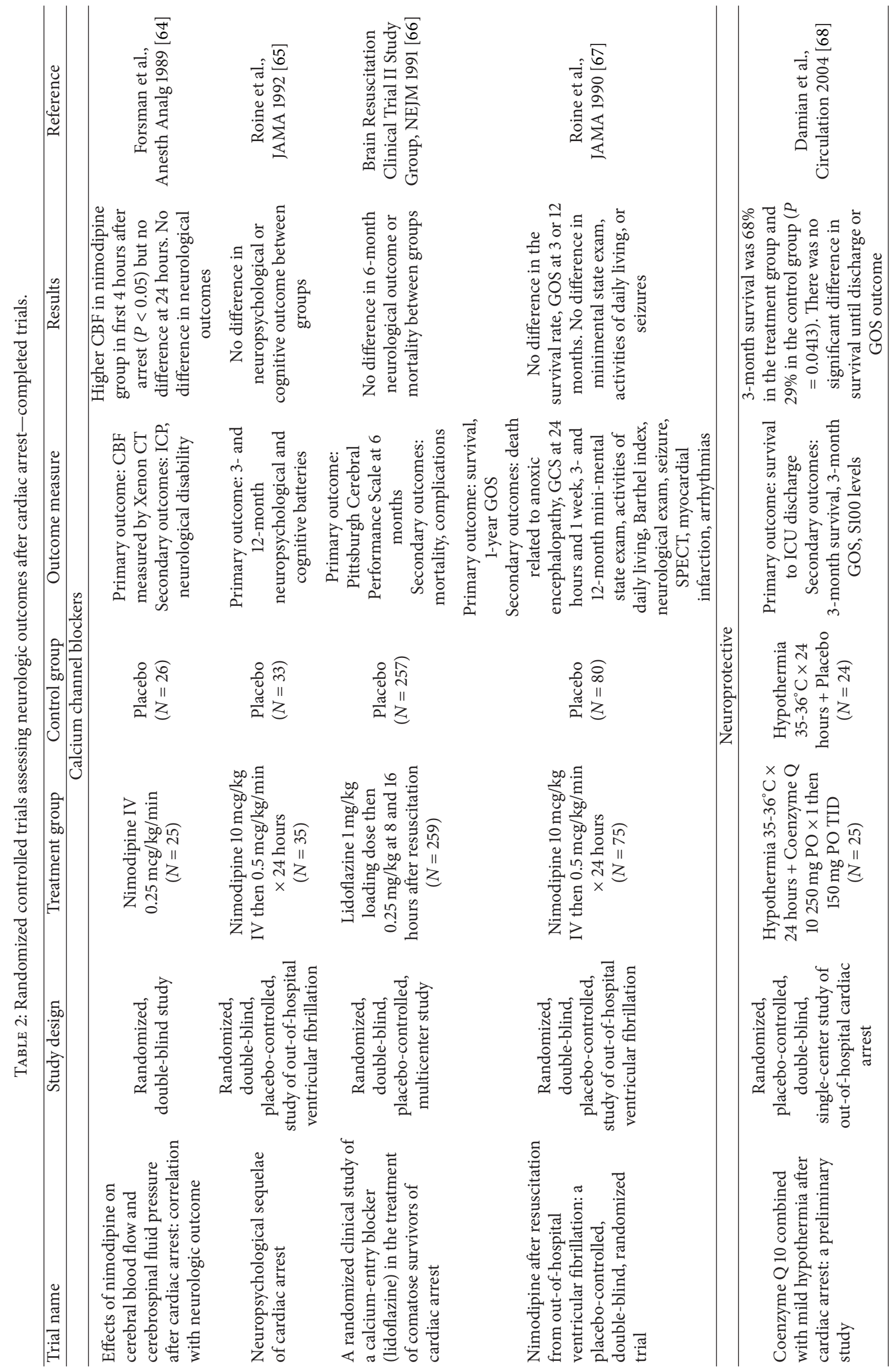




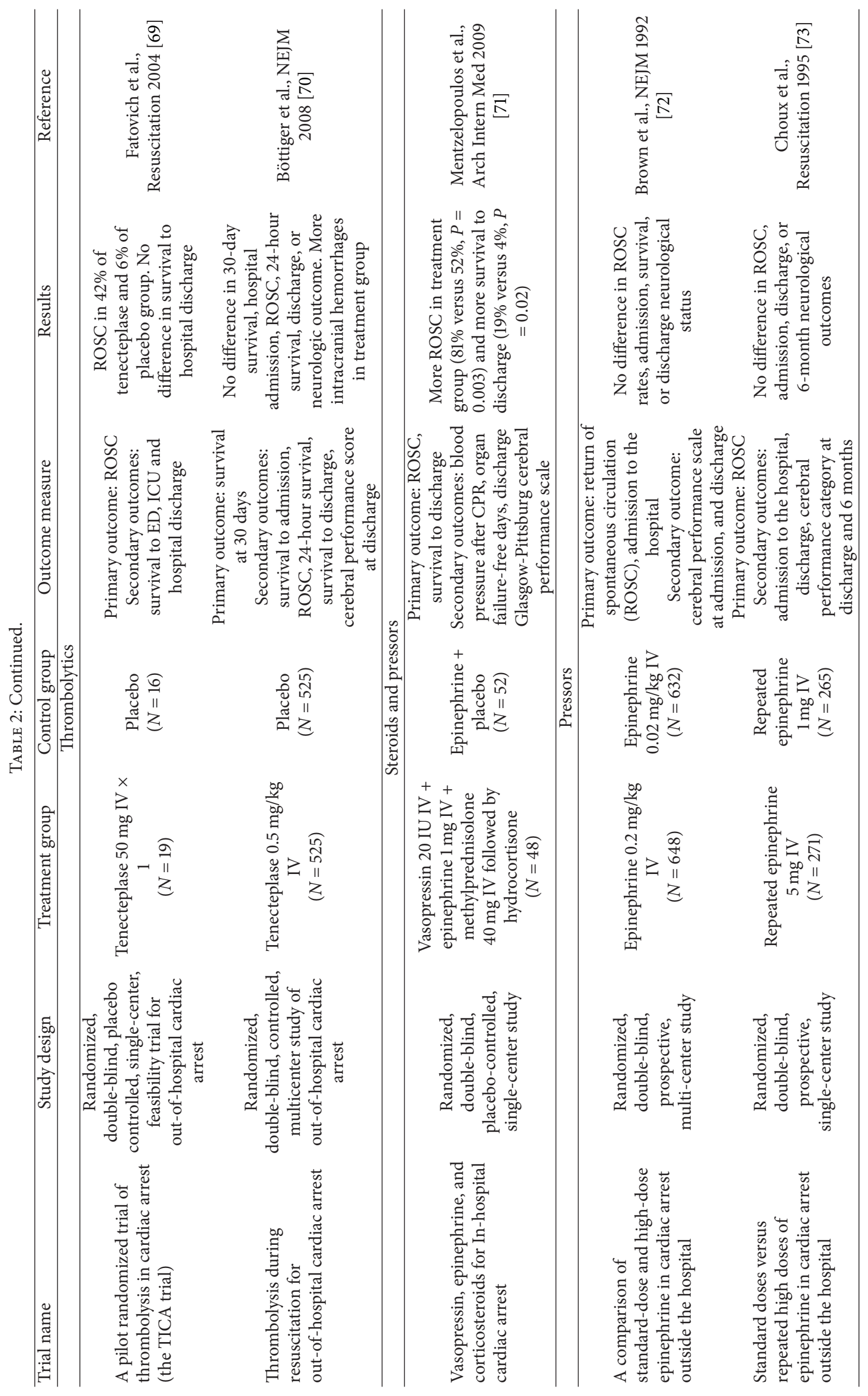




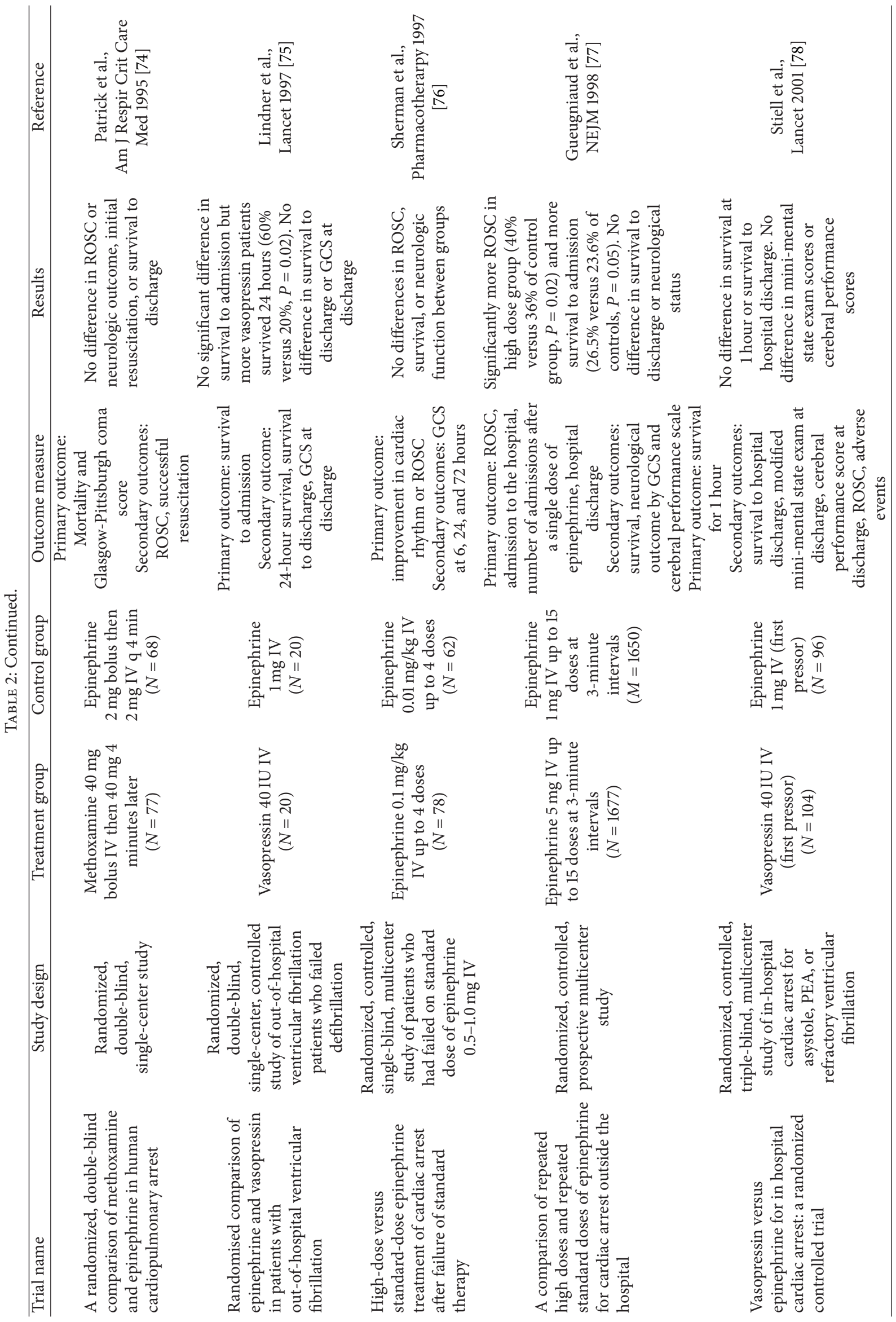




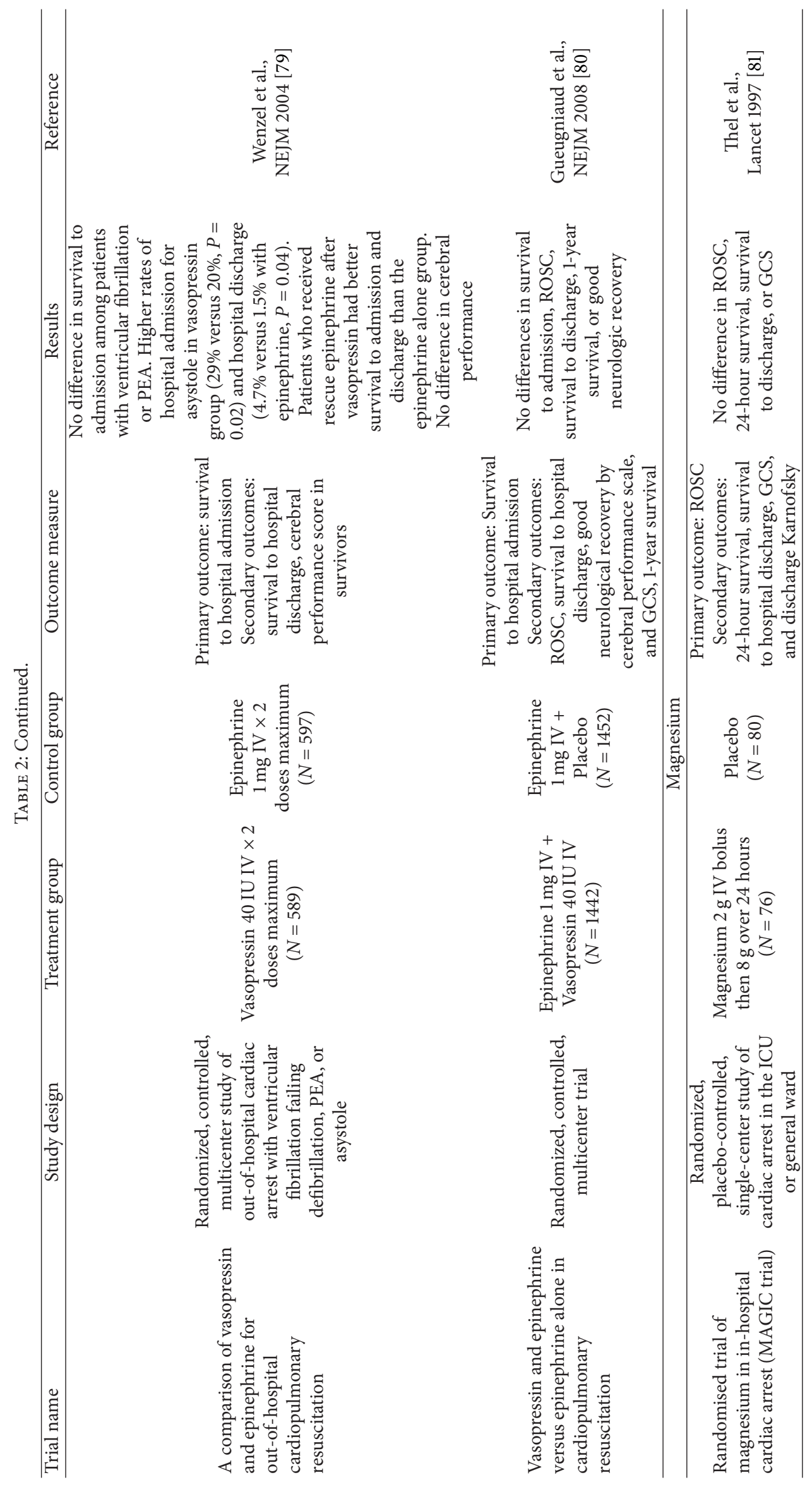




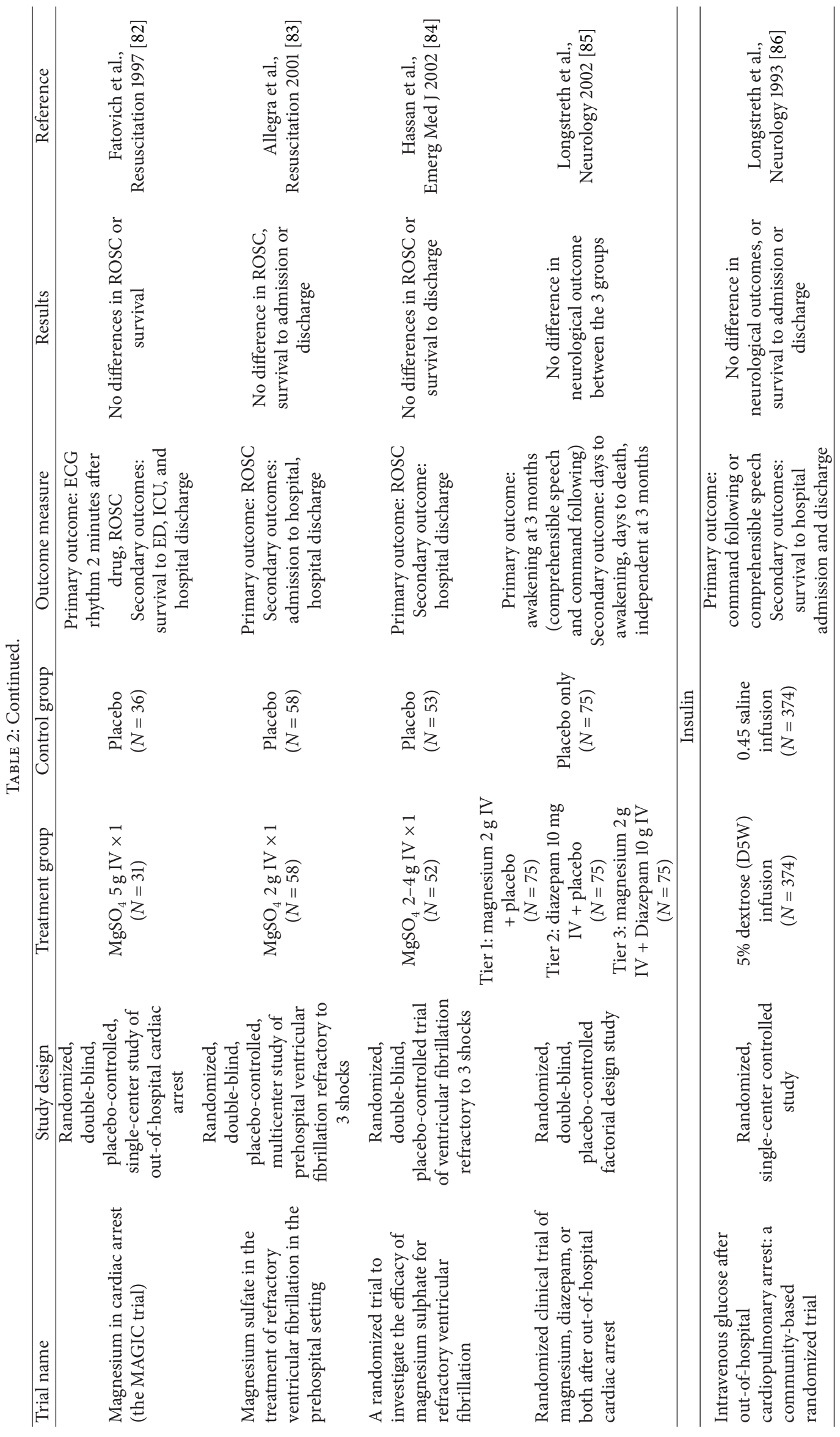




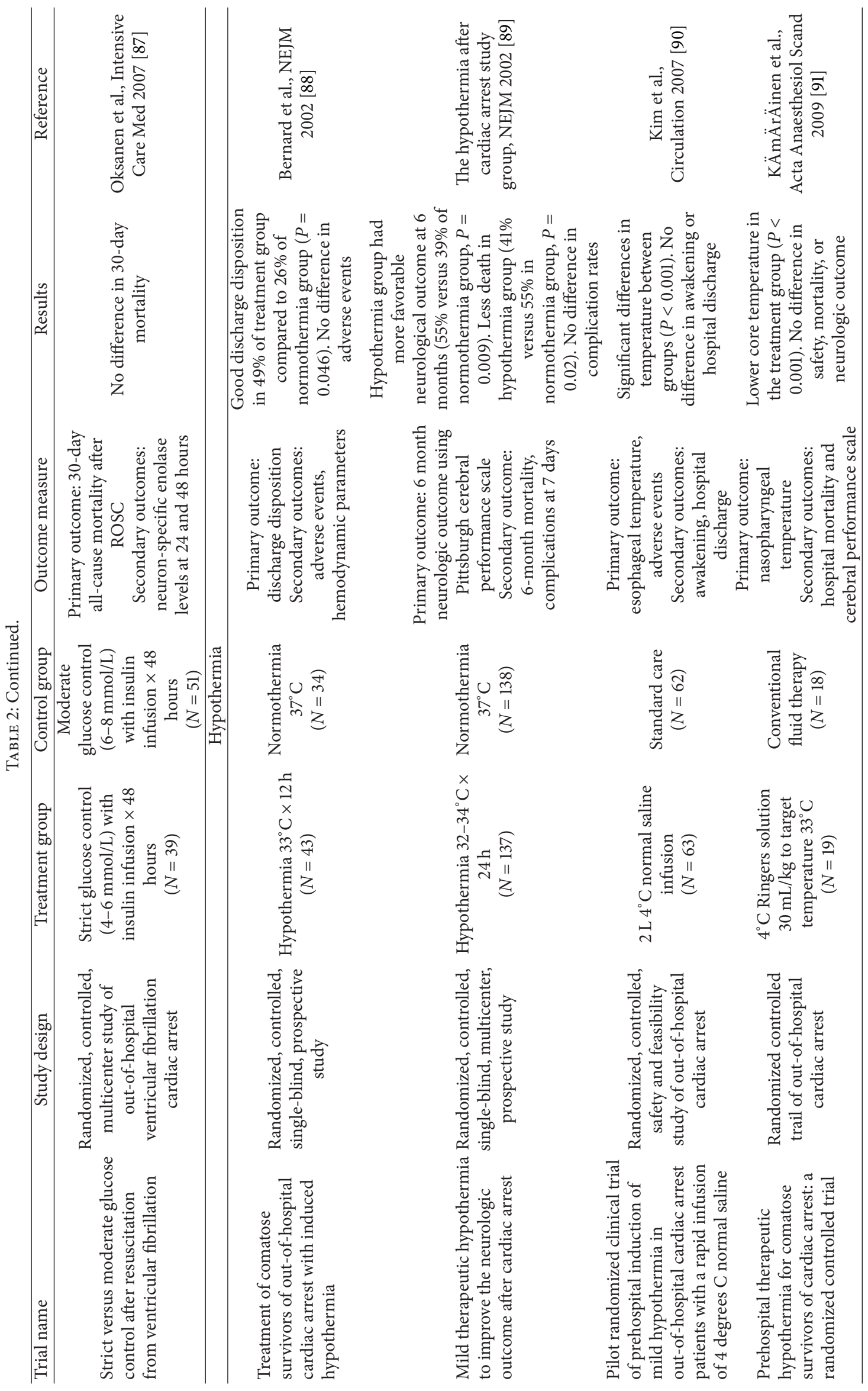




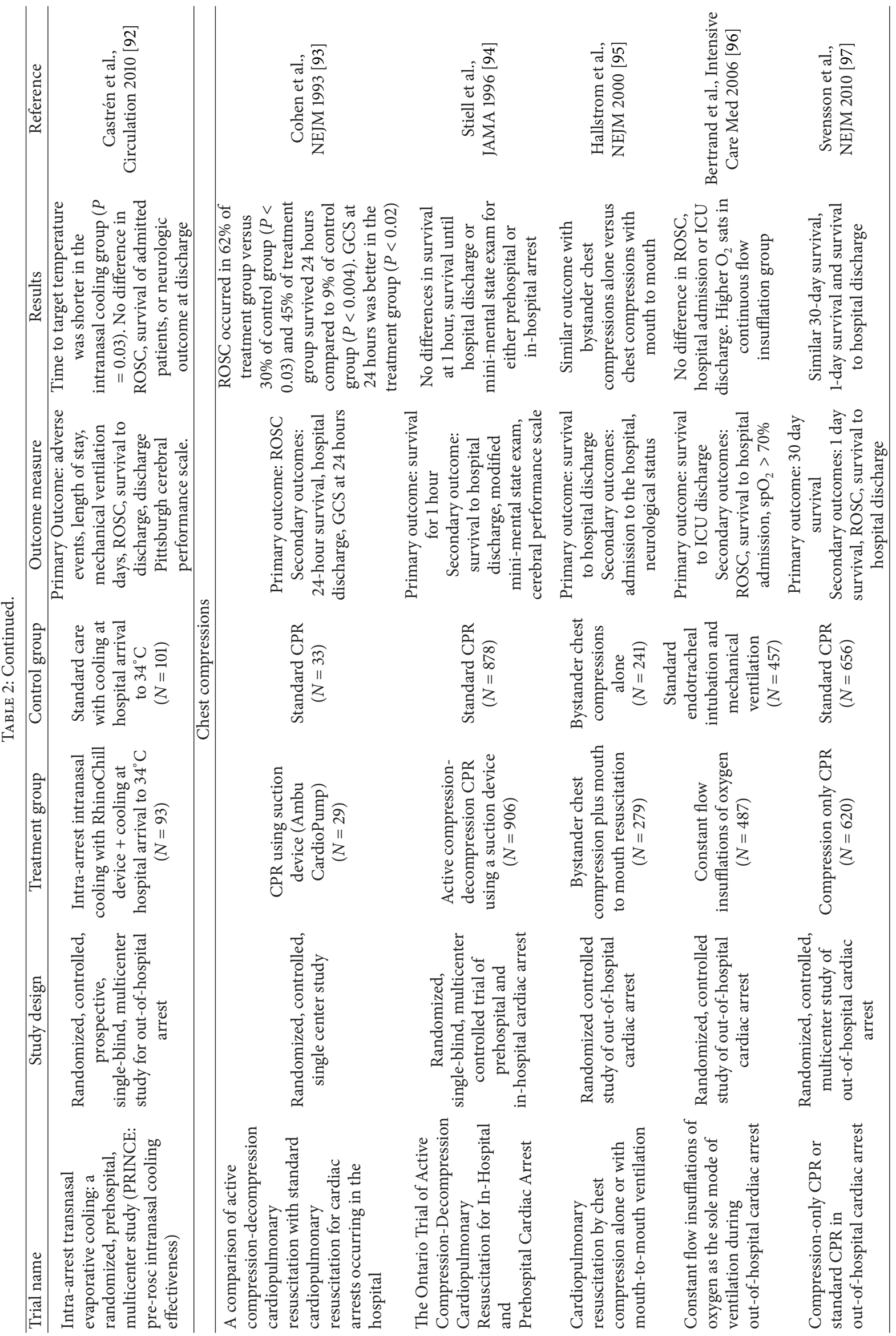




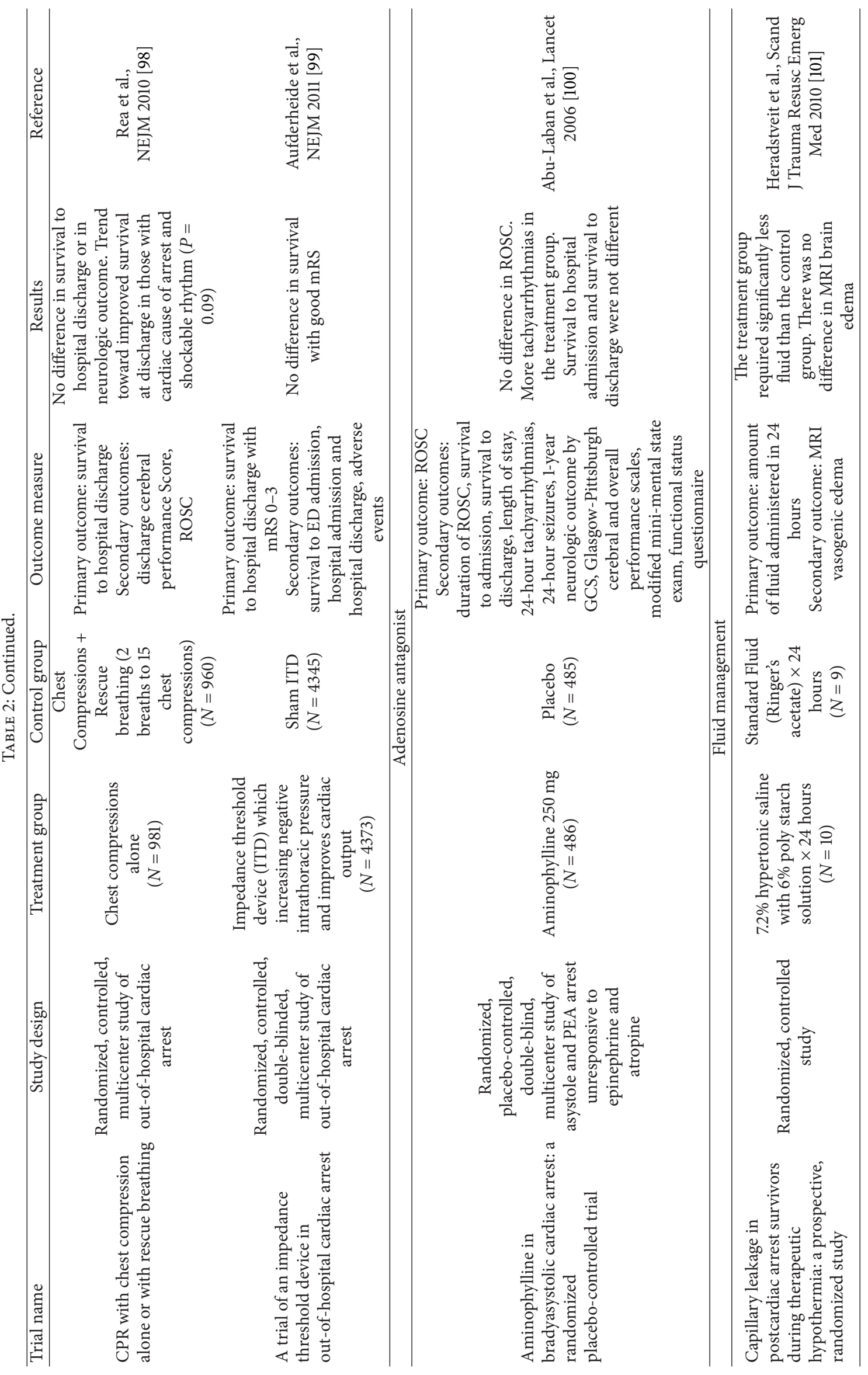




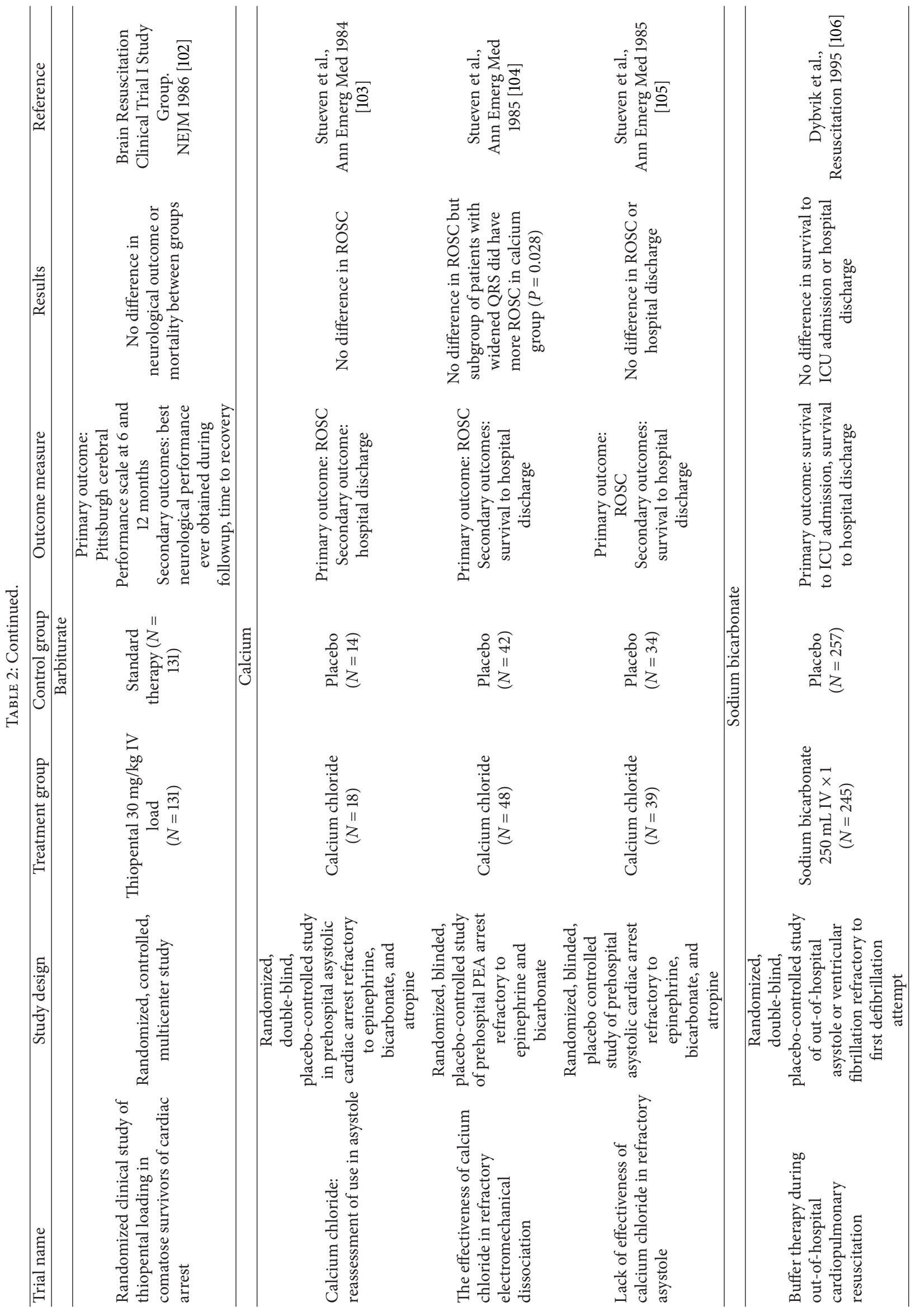




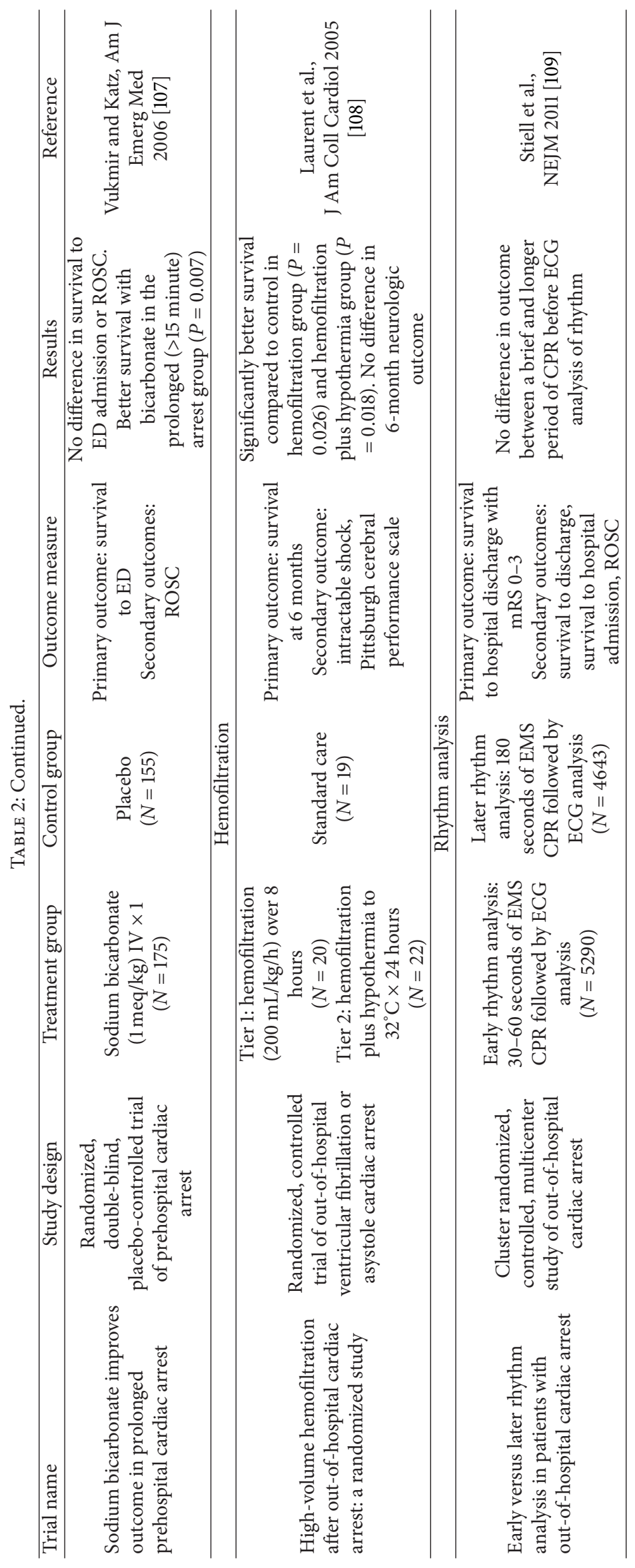


tested an intervention published in English between 1980 and 2012, were included. Only trials examining mortality or neurologic outcome as a primary or secondary endpoint were reviewed. Only trials specific to SAH (not trials that included other neurocritical diagnoses or brain injury diagnoses) were included. Cardiac arrest trials included both out-of-hospital and in-hospital arrest and all arrest rhythms were included. Post hoc analyses of preexisting trials were not reviewed. If phase III results of a trial were available, earlier phases of the same trial were not included in analysis unless the patient population or methodology differed substantially.

A PubMed search of the term "subarachnoid hemorrhage" and "neurologic outcome" with the limits of human, age $>18$, English and randomized, controlled trial yielded 23 results. A PubMed search of the term "subarachnoid hemorrhage" and "mortality" with the limits of human, age $>18$, English and randomized, controlled trial yielded 78 results. An additional review of articles identified by a broader search of "subarachnoid hemorrhage" with the limits of human, age > 18, English and randomized, controlled trial yielded 244 results. Review of these studies yielded 57 aneurysmal SAH trials that met inclusion criteria and were analyzed. A pubmed search of the terms "cardiac arrest" and "neurologic outcome" with the limits of human, English, age $>18$ and randomized, controlled trial yielded 21 results. A PubMed search of the terms "cardiac arrest" and "mortality" with the limits of human, English, age $>18$ and randomized, controlled trial yielded 197 results. Review of these studies yielded 46 cardiac arrest trials that met inclusion criteria and were analyzed.

Clinicaltrials.gov was searched for ongoing interventional trials in cardiac arrest and aneurysmal subarachnoid hemorrhage. Only ongoing studies that were open and recruiting or preparing to recruit were included. Terminated studies were excluded from review. A search of ongoing studies on clinicaltrials.gov for the term "subarachnoid hemorrhage", limited to interventional studies of adults $\geq 18$ years old, produced 86 results and a search for the term "cardiac arrest" limited to interventional studies of adults with neurologic outcomes produced 46 results. Of these, 25 ongoing SAH trials and 14 cardiac arrest trials met the criteria for review.

\section{Results}

3.1. Trials Analyzed. A total of 142 trials ( $82 \mathrm{SAH}, 60$ cardiac arrest) met review criteria. Of these, 103 were published in peer-reviewed journals and 39 were ongoing studies. Fifty-seven published randomized, controlled studies were identified in the SAH population and 46 in the cardiac arrest population. These studies are reviewed in detail in Tables 1 and 2. Additionally, 25 ongoing SAH trials and 14 ongoing cardiac trials were reviewed (Tables 3 and 4).

3.2. Interventions Studied. The main hypothetical mechanisms of intervention tested in published SAH trials were related to treating or preventing delayed cerebral ischemia $(N=40,70 \%)$, preventing aneurysm rebleeding $(N=5$, $9 \%)$, improving aneurysm repair technique $(N=5,9 \%)$, improving fluid balance $(N=2,4 \%)$, and others $(N=3,5 \%)$. Among ongoing SAH trials, mechanisms of study include treating or preventing delayed cerebral ischemia $(N=19$, $76 \%)$, limiting rebleeding $(N=1,4 \%)$, improving aneurysm repair $(N=1,4 \%)$, seizure control $(N=2,8 \%)$, and other $(N=2,8 \%)$. There are no published or ongoing SAH clinical trials that focus on treating acute brain injury after aneurysm rupture.

Conversely, the main mechanisms of intervention studied in published cardiac arrest trials focused on acute intervention to treat and limit early brain injury. All 46 (100\%) published cardiac arrest trials focused on the acute time frame (first few hours) after cardiac arrest. Interventions studied included decreasing cerebral metabolic demand with hypothermia or barbiturate $(N=6,13 \%)$, high-quality chest compressions or pressor use to return cerebral blood flow $(N=16,35 \%)$, electrolyte/metabolic optimization with calcium, magnesium, sodium bicarbonate or insulin administration $(N=12,26 \%)$, neuroprotective drugs including calcium channel blockers $(N=5,11 \%)$, thrombolysis to treat the underlying cause of cardiac arrest $(N=2,4 \%)$ and other $(N=5,11 \%)$. Among ongoing cardiac arrest trials, mechanisms of study include decreasing cerebral metabolic demand with hypothermia $(N=9,64 \%)$, high-quality chest compressions to return cerebral blood flow $(N=$ $2,14 \%)$ electrolyte/metabolic optimization with magnesium $(N=1,7 \%)$, neuroprotective drugs $(N=1,7 \%)$, and monitoring cerebral oxygenation $(N=1,7 \%)$. A detailed list of interventions from published and ongoing studies in both the SAH and cardiac arrest population are listed in Table 5.

3.3. Outcome Measures. The most common neurological outcomes assessed in the SAH trials were delayed cerebral ischemia ( $N=24,42 \%)$, functional outcome (Glasgow outcome scale, modified Rankin scale or functional outcome scale, $N=24,42 \%)$, angiographic or transcranial Doppler vasospasm $(N=6,11 \%)$, and death $(N=4,7 \%)$. Among cardiac arrest trials, the most often assessed neurological outcomes were the Pittsburgh cerebral performance score $(N=18,40 \%)$, Glasgow outcome score or modified Rankin Score $(N=4,9 \%)$, Glasgow coma score $(N=4,9 \%)$, awakening and command following $(N=3,7 \%)$, cognitive or neuropsychological testing $(N=1,2 \%)$, "disability" $(N=1$, $2 \%)$, death $(N=13,30 \%)$, discharge disposition $(N=1,2 \%)$ and others $(N=1,2 \%)$.

3.4. Trial Results. Of the clinical trials reviewed for SAH, $30 \%(17 / 57)$ showed that the intervention tested had a statistically significant impact on neurological outcome or mortality. These include studies of nimodipine $[4-6,8,110]$, phase II data for nicardipine implants during aneurysm clipping [13], the neuroprotectants edavarone [21] and nizofenone [20], pravastatin [25], early aneurysm surgery [28], endovascular coiling [29-31], cilostazol [41], methylprednisolone [44], erythropoietin [45], and fasudil [57, 58]. Similarly, $30 \%(17 / 57)$ of studies showed a positive impact on delayed cerebral ischemia, infarction, angiographic or TCD vasospasm, though there was incomplete overlap with the 


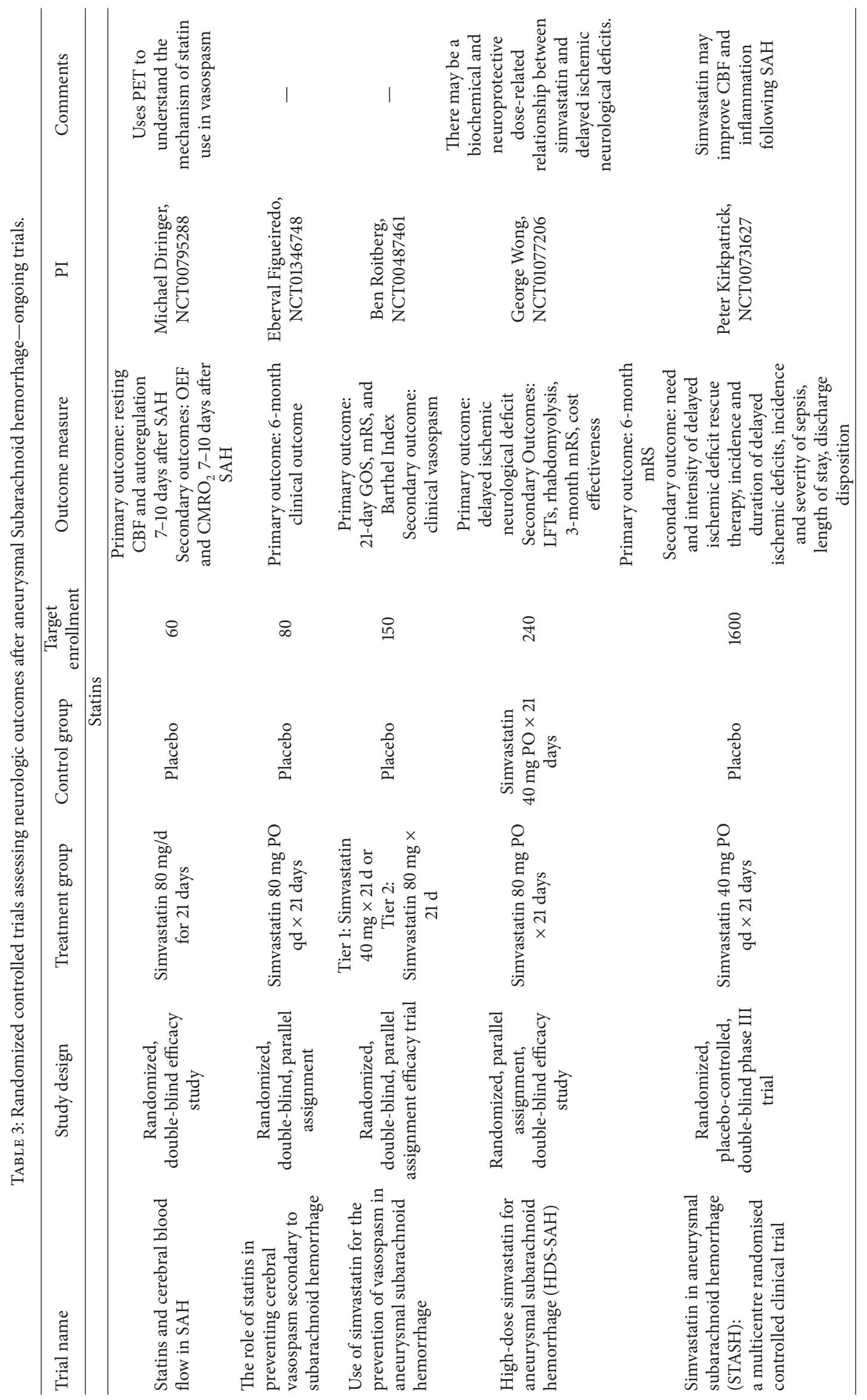




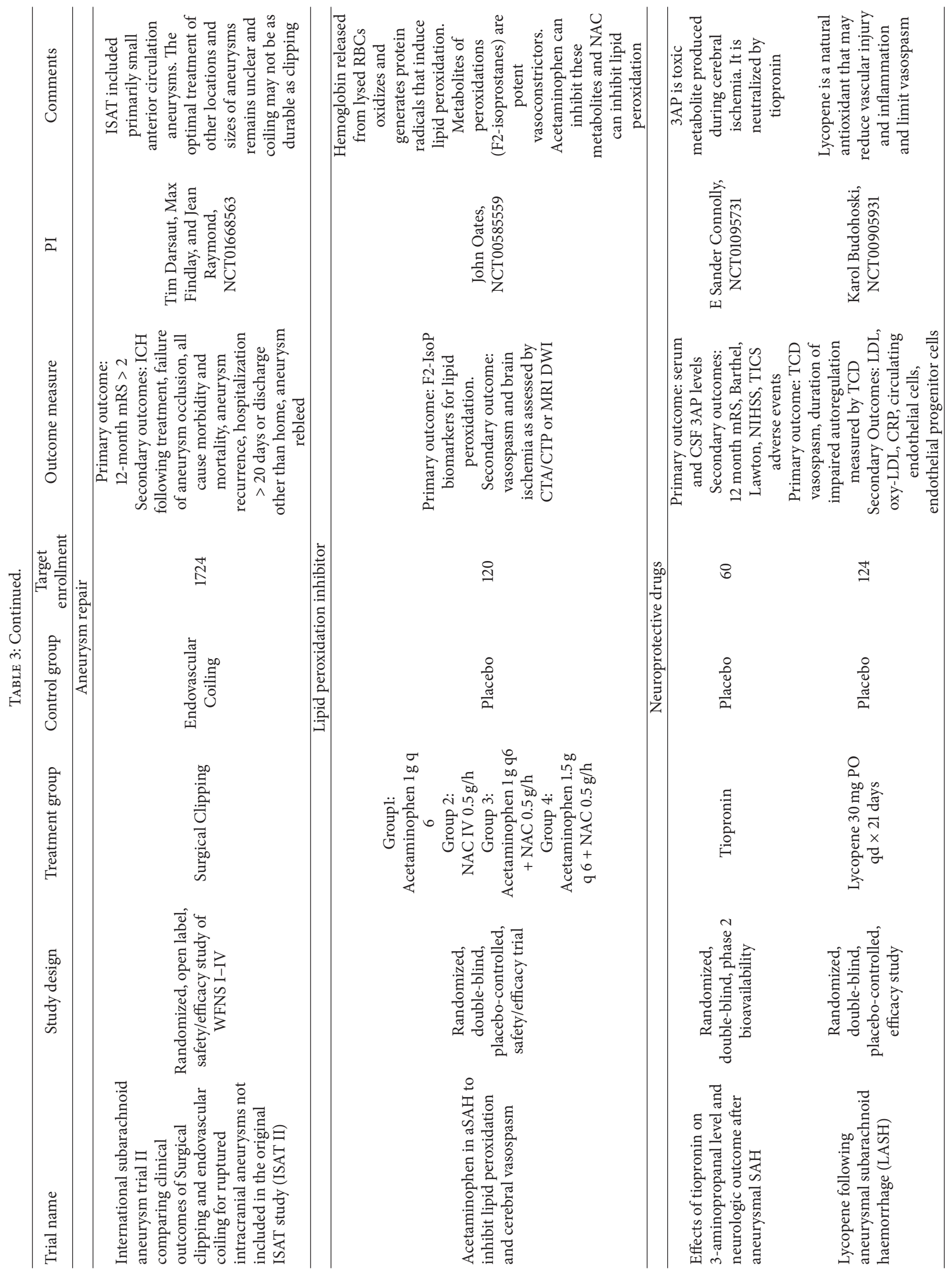




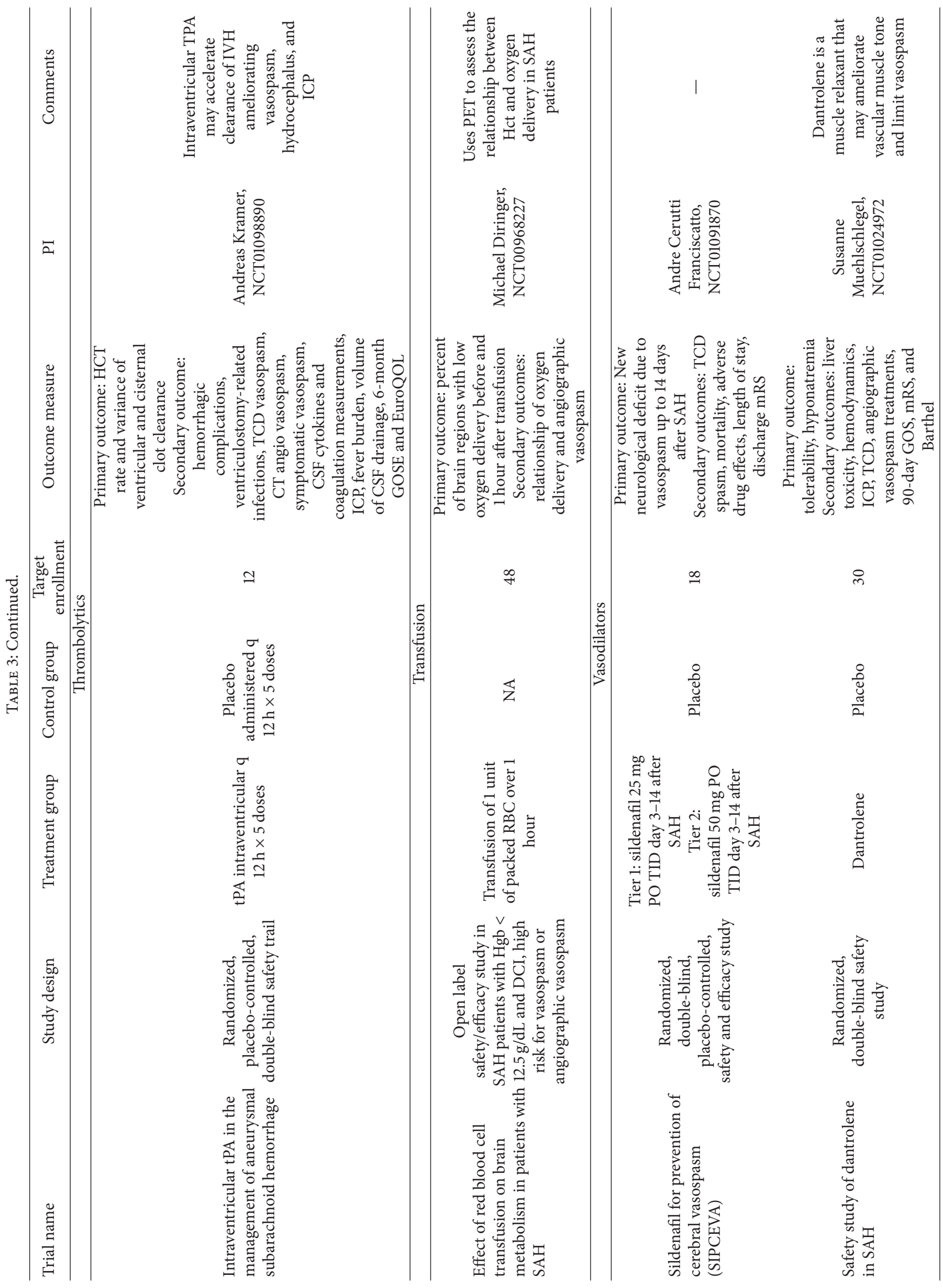




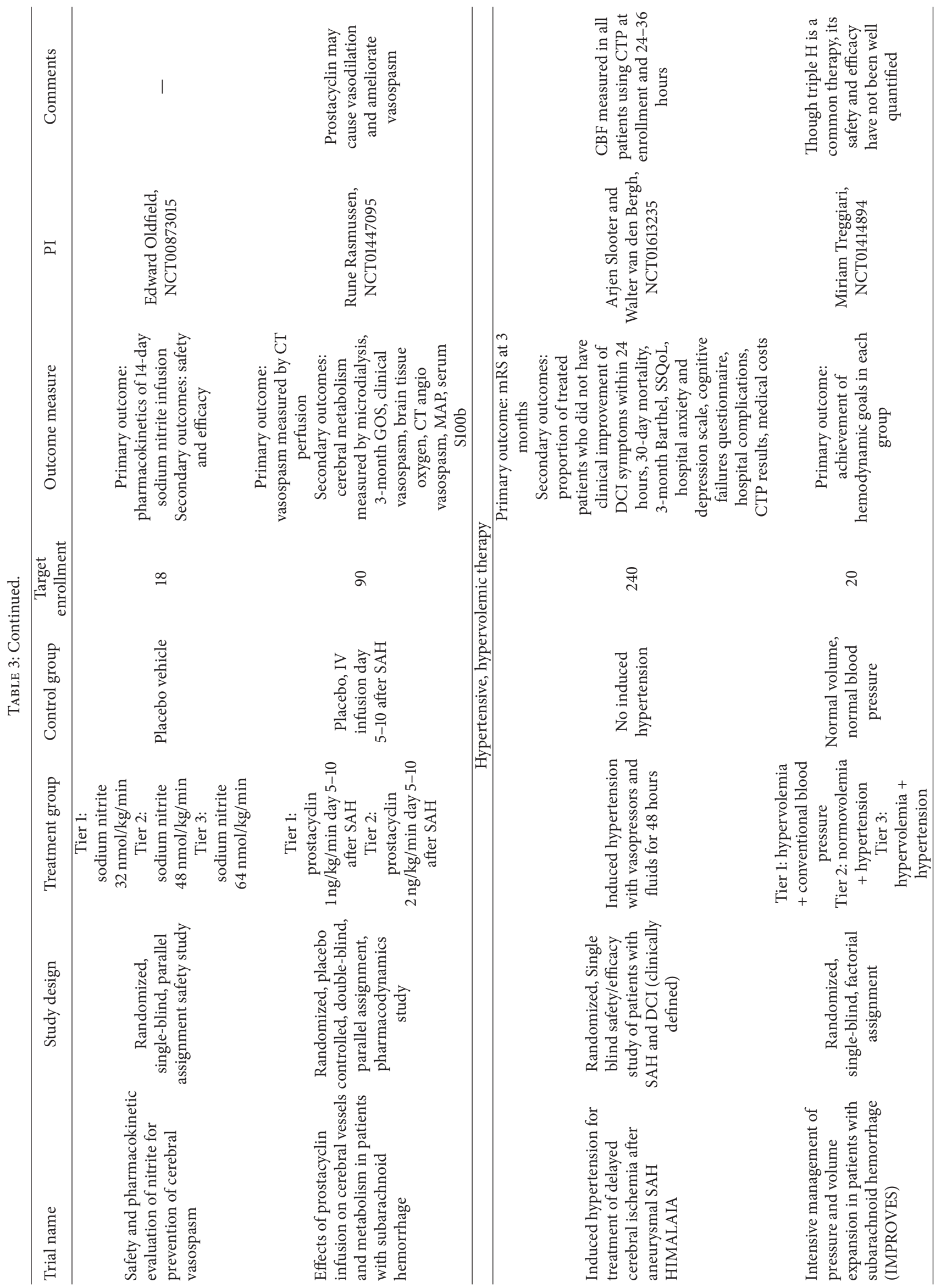




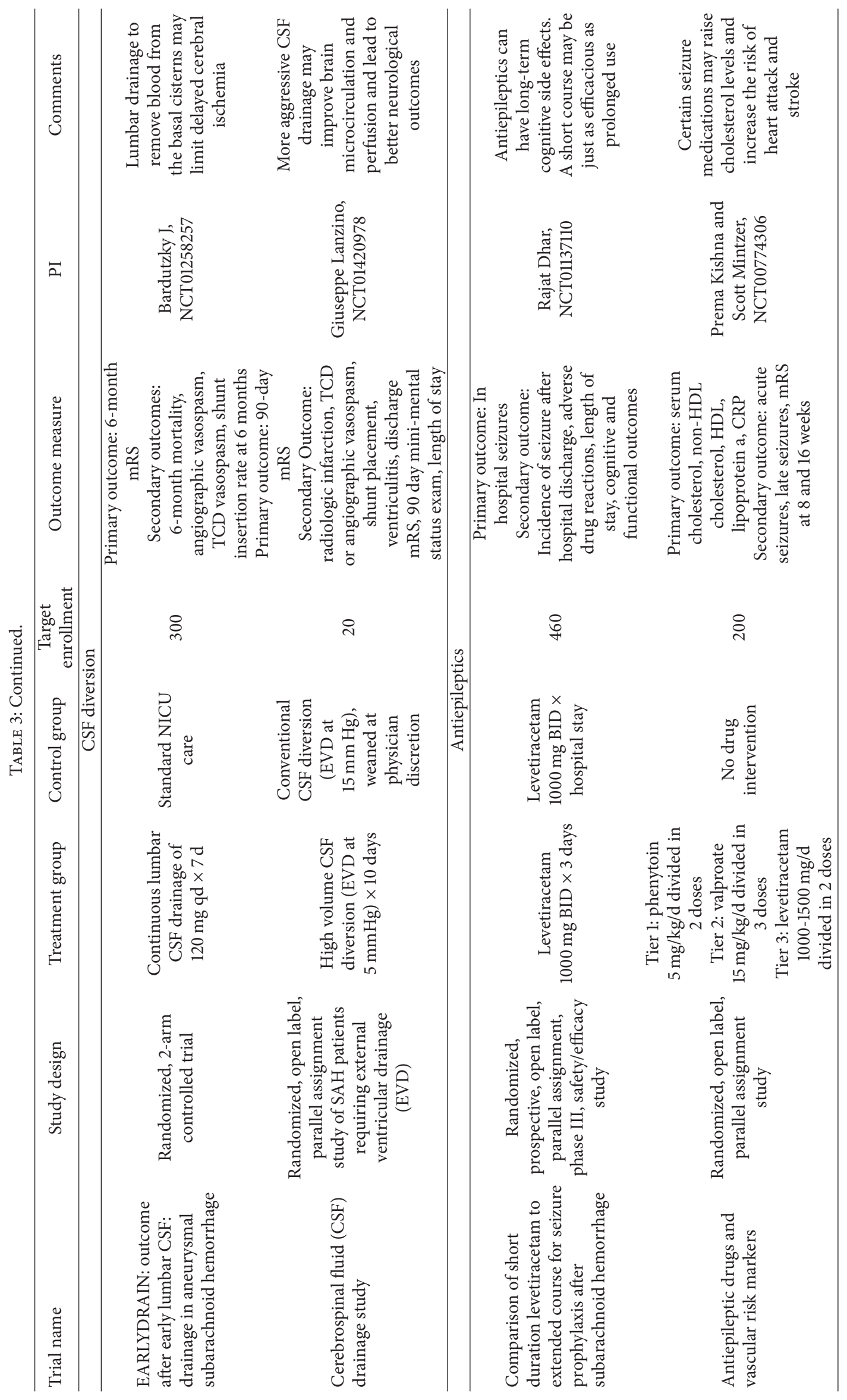




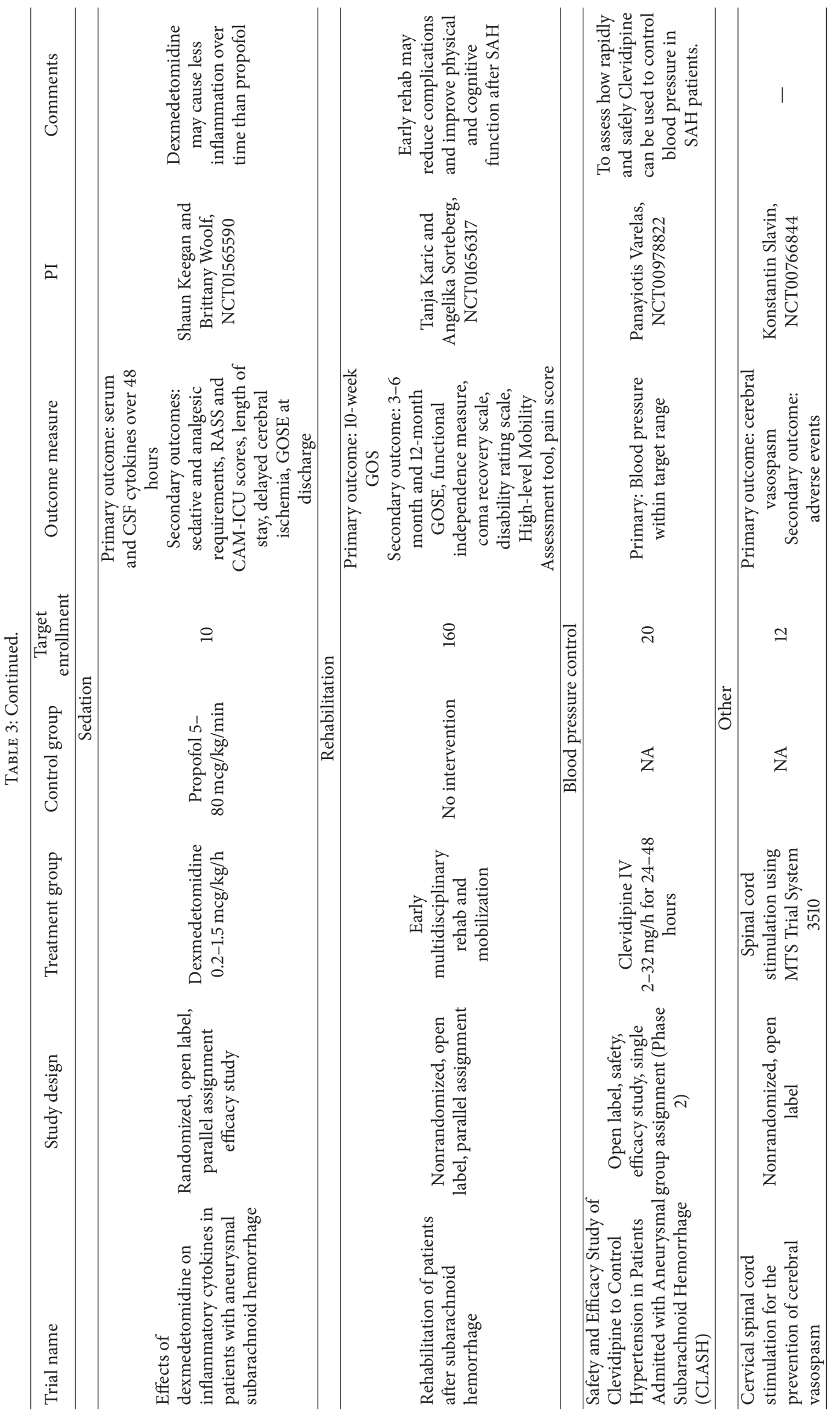




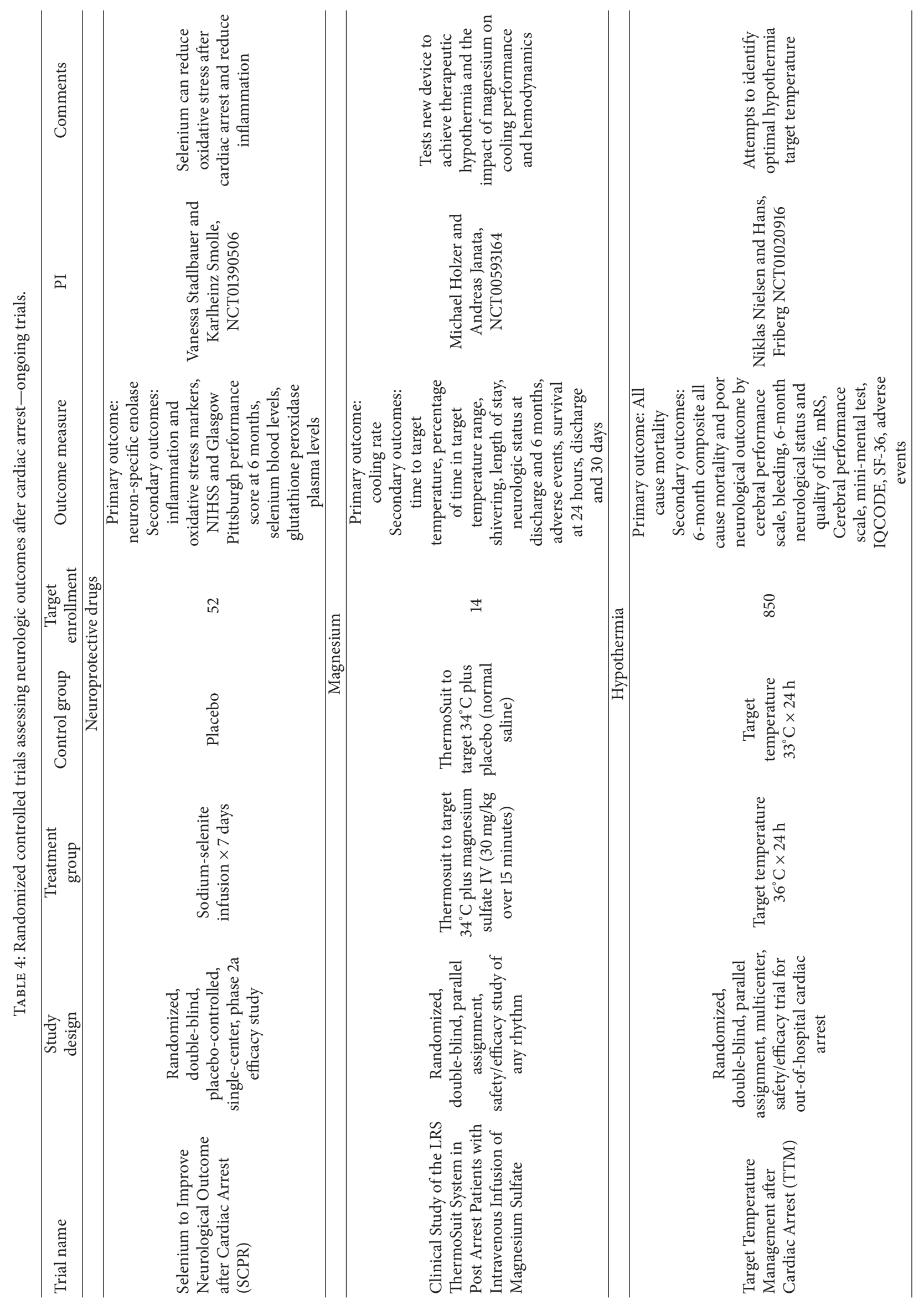




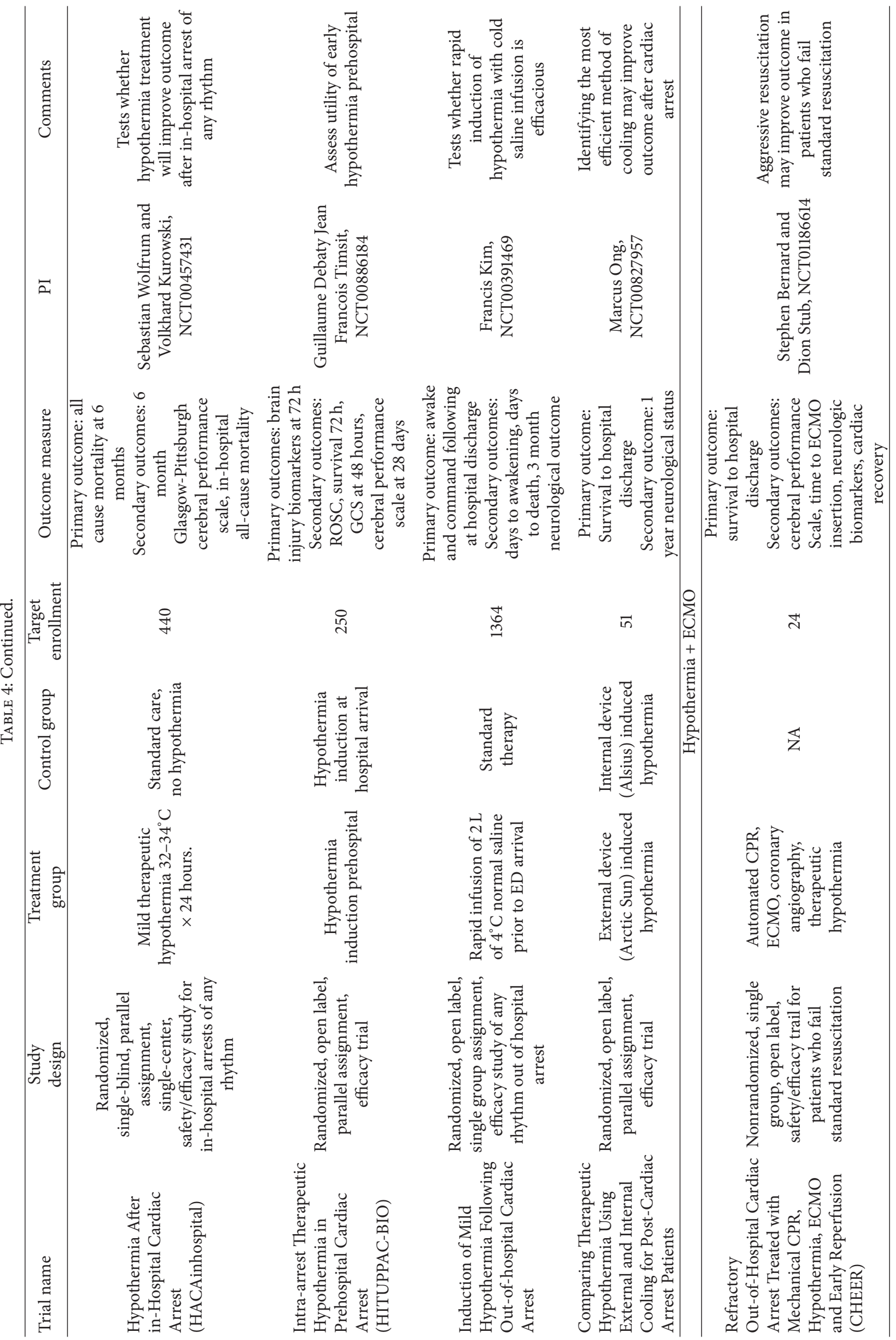




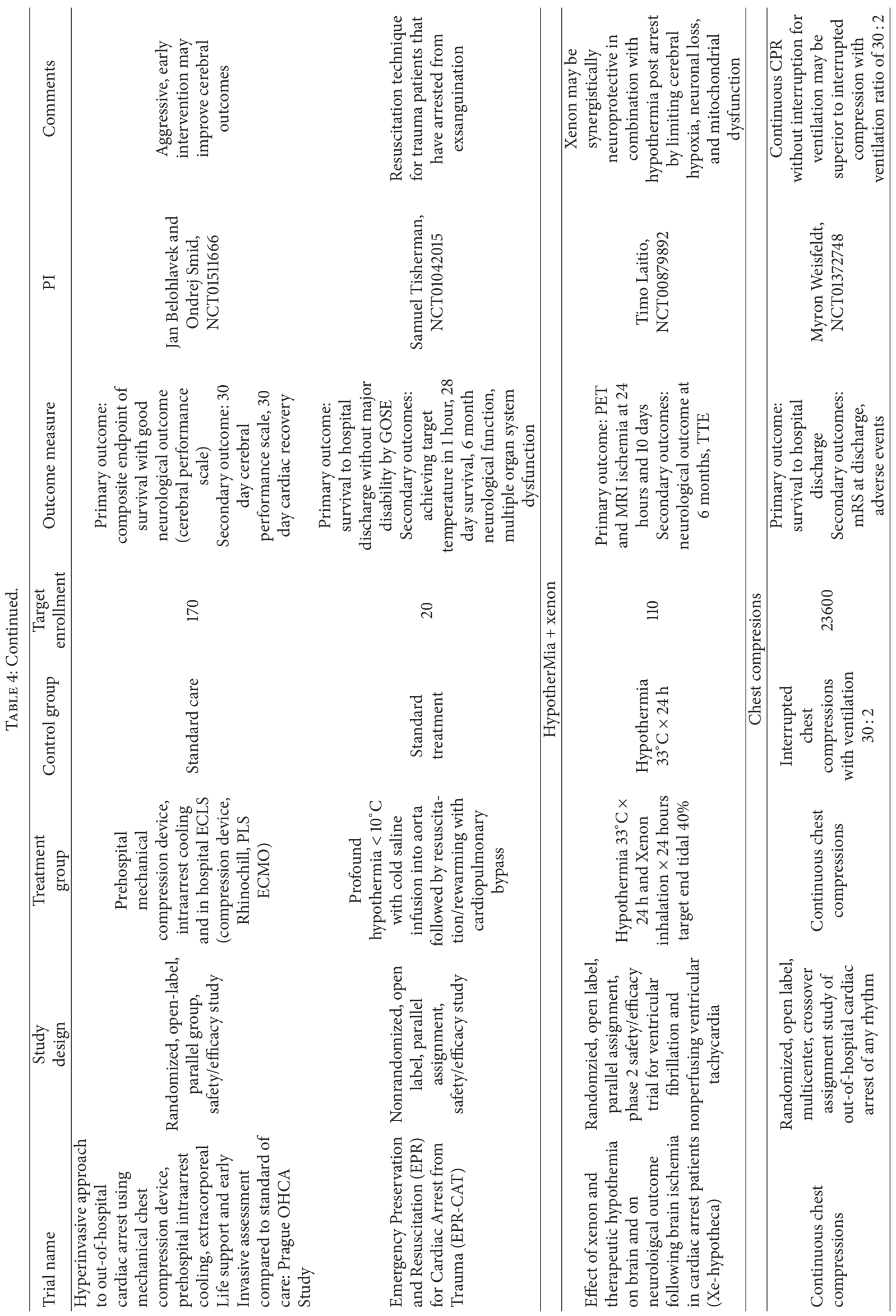




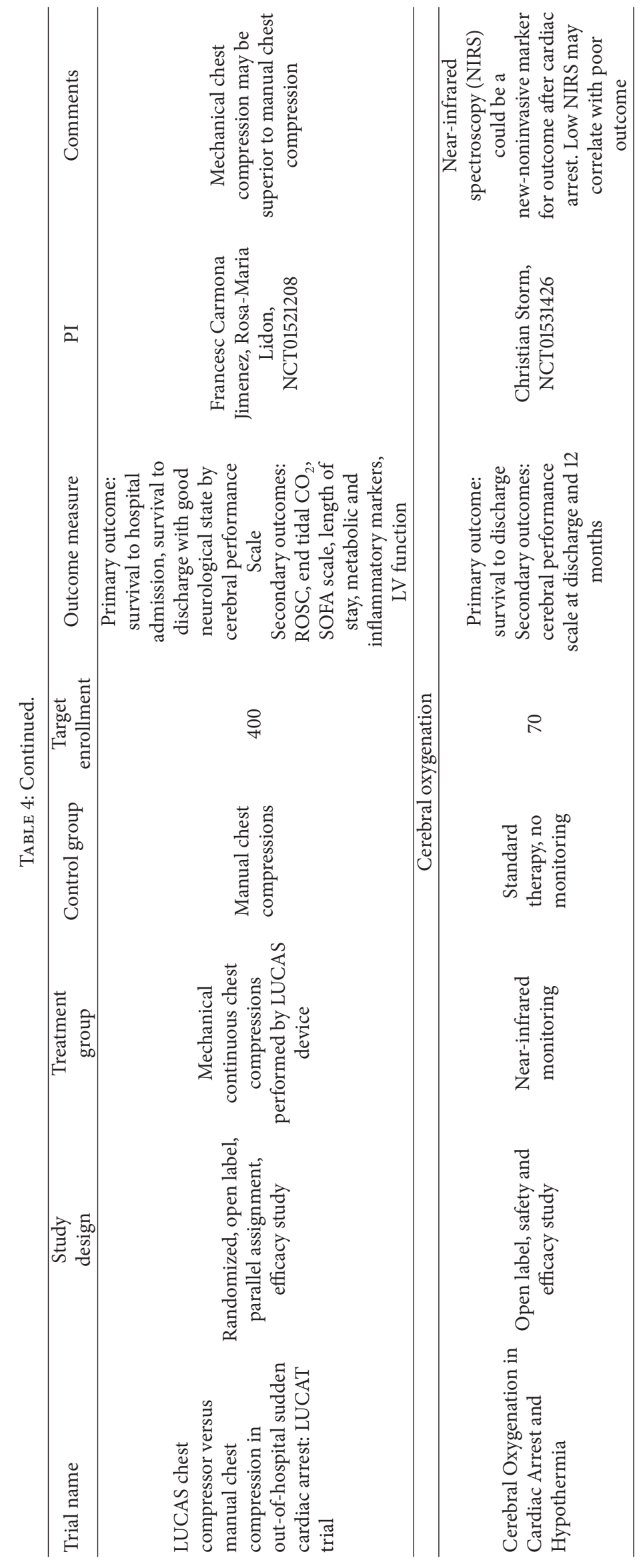


TABLE 5: Number of randomized, controlled trials published and ongoing for aneurysmal subarachnoid hemorrhage and cardiac arrest.

\begin{tabular}{|c|c|c|c|c|}
\hline \multirow{2}{*}{ Intervention } & \multicolumn{2}{|c|}{ SAH } & \multicolumn{2}{|c|}{ Cardiac arrest } \\
\hline & $\begin{array}{c}\text { Published } \\
N(\%)\end{array}$ & $\begin{array}{c}\text { Ongoing } \\
N(\%)\end{array}$ & $\begin{array}{c}\text { Published } \\
N(\%)\end{array}$ & $\begin{array}{c}\text { Ongoing } \\
N(\%)\end{array}$ \\
\hline Calcium channel blockers & $10(18)$ & 0 & $4(9)$ & 0 \\
\hline Antifibrinolytics & $5(9)$ & 0 & 0 & 0 \\
\hline Neuroprotective drugs & $5(9)$ & $2(8)$ & $1(2)$ & $1(7)$ \\
\hline Statins & $4(7)$ & $5(20)$ & 0 & 0 \\
\hline Aneurysm clip or coil & $4(7)$ & $1(4)$ & NA & NA \\
\hline Lipid peroxidation inhibitor & $4(7)$ & $1(4)$ & 0 & 0 \\
\hline Thrombolytics & $3(5)$ & $1(4)$ & $2(4)$ & 0 \\
\hline Antiplatelets & $3(5)$ & 0 & 0 & 0 \\
\hline Steroids & $3(5)$ & 0 & $1(2)$ & 0 \\
\hline Transfusion/blood products/erythropoietin & $3(5)$ & $1(4)$ & 0 & 0 \\
\hline Vasodilators & $3(5)$ & $4(16)$ & 0 & 0 \\
\hline Pressors or $\mathrm{HHH}$ & $2(4)$ & $2(8)$ & $9(19.5)$ & 0 \\
\hline Magnesium & $2(4)$ & 0 & $5(11)$ & $1(7)$ \\
\hline Rho-kinase inhibitor (fasudil) & $2(4)$ & 0 & 0 & 0 \\
\hline Adrenergic blockade & $1(2)$ & 0 & 0 & 0 \\
\hline Endovascular therapy & $1(2)$ & 0 & NA & NA \\
\hline Insulin/glucose control & $1(2)$ & 0 & $2(4)$ & 0 \\
\hline Hypothermia & $1(2)$ & 0 & $5(11)$ & $9(64)$ \\
\hline CSF diversion & 0 & $2(8)$ & 0 & 0 \\
\hline Antiepileptics & 0 & $2(8)$ & 0 & 0 \\
\hline Sedation & 0 & $1(4)$ & 0 & 0 \\
\hline Rehabilitation & 0 & $1(4)$ & 0 & 0 \\
\hline Blood pressure & 0 & $1(4)$ & 0 & 0 \\
\hline Other & 0 & $1(4)$ & 0 & 0 \\
\hline Chest compressions & NA & NA & $7(15)$ & $2(14)$ \\
\hline Adenosine antagonist & 0 & 0 & $1(2)$ & 0 \\
\hline Fluid management & 0 & 0 & $1(2)$ & 0 \\
\hline Barbiturate & 0 & 0 & $1(2)$ & 0 \\
\hline Cerebral oxygenation & 0 & 0 & 0 & $1(7)$ \\
\hline Calcium chloride & 0 & 0 & $3(7)$ & 0 \\
\hline Sodium bicarbonate & 0 & 0 & $2(4)$ & 0 \\
\hline Hemofiltration & 0 & 0 & $1(2)$ & 0 \\
\hline Rhythm analysis & 0 & 0 & $1(2)$ & 0 \\
\hline Total & 57 & 25 & 46 & 14 \\
\hline
\end{tabular}

above studies that showed outcome benefit. Eight studies found both a significant improvement in delayed cerebral ischemia/vasospasm/infarction and outcome including studies of nimodipine $[4,6,8]$, nicardipine implants in the basal cistern [13], edavarone [21], pravastatin [25], fasudil [57], and erythropoietin [45]. Nine studies found a benefit for decreasing delayed cerebral ischemia/vasospasm/infarction but no neurologic outcome benefit including studies of IV nicardipine $[10,11]$, eicosapentaenoic acid (omega-3 fatty acid) [22], the neuroprotectant NA-1 [23], simvastatin [24], tirilazad [34], intracisternal rTPA [36, 38], and clazosentan
$[49,50]$. Three studies found improved neurologic outcome despite an insignificant effect on delayed cerebral ischemia/vasospasm/infarction including studies of cilostazol [41], methylprednisolone [44], and fasudil [58].

Among the cardiac arrest trials, 13\% (6/46) demonstrated neurologic or mortality benefit. Improved mortality rates were demonstrated with mild therapeutic hypothermia [89], coenzyme Q10 [68], vasopressin plus epinephrine plus methylprednisolone [71], active compression-decompression CPR [93], and hemofiltration [108]. Improved neurological outcome was demonstrated with early mild therapeutic 
hypothermia for ventricular fibrillation and pulseless ventricular tachycardia arrests $[88,89]$, and one study of active compression-decompression CPR [93], though a larger study of active compression-decompression was negative [94].

3.5. Trial Overlap. Though nimodipine has demonstrated mortality and functional outcome benefit in SAH [4-6, 8, $110]$, it has shown no benefit in cardiac arrest trials [64, 65 , 67]. Similarly, intracisternal thrombolysis showed some benefit in reducing delayed cerebral ischemia and infarction after SAH [36, 38], but intravenous tenecteplase showed no long-term benefit and, in fact, increased intracranial hemorrhage after cardiac arrest $[69,70]$. Neither magnesium [53, 54, 81-85] nor intensive insulin [59, 87] has proven beneficial after SAH or cardiac arrest. Though hypothermia $[88,89]$ has been the single most effective treatment for cardiac arrest (the number needed to treat to prevent one death is 7 and the number needed to treat to produce favorable neurological outcome is 6), it has not proven useful in the context of aneurysm surgery after SAH [60]. There is little mechanistic overlap in ongoing randomized, controlled trials of SAH and cardiac arrest patients.

\section{Discussion}

In this paper, a direct comparison is made between randomized, controlled clinical trials that evaluate mortality or neurologic outcome after SAH and cardiac arrest. Though $28 \%$ of SAH studies showed some neurologic outcome benefit in the intervention group, only nimodipine $[4-6,8,110]$, fasudil $[57,58]$, and endovascular coiling [29-31] have been found to consistently improve outcome in multiple, multicenter randomized controlled trials. Smaller studies [8, 41, $58]$, single center [21, 44], or phase II safety and feasibility studies [13, 25, 45] have shown outcome benefit, but still require larger efficacy trials before integration into standard practice. Among cardiac arrest trials, only mild therapeutic hypothermia has been shown to improve both mortality and neurologic outcome $[88,89]$. Little overlap in trial results or mechanisms of study was identified in these different patient populations.

Methodological differences in the timing, duration, neurological severity, and outcomes studied may explain some of the differences in trial results between SAH and cardiac arrest populations. First, the timing of intervention for SAH and cardiac arrest trials is quite different. With the exception of aneurysm repair and aneurysm rebleeding trials (some of which were carried out in the era of delayed surgical treatment), the vast majority of $\mathrm{SAH}$ trials focus on the delayed cerebral ischemia period. Conversely, all cardiac arrest trials are directed at intervening against early brain injury. The difference in time frames studied may explain, in part, the variable results for mild therapeutic hypothermia in each population. Unlike the cardiac arrest trials, which applied hypothermia either prior to ED arrival [88] or within a median of 105 minutes from return of spontaneous circulation (ROSC) [89] for a duration of 12-24 hours, hypothermia was applied in the IHAST trial at a median of two days from
SAH onset and only for a brief time (median 5-6 hours) [60]. Second, patient selection may result in variable trial results for hypothermia. For example, hypothermia for cardiac arrest was used for comatose survivors, while relatively neurologically intact patients (WFNS I-III) were studied in the IHAST trial. Finally, outcome measures differ in the cardiac arrest and SAH literature. Many cardiac trials measure 30day or discharge mortality or neurologic outcome, while SAH trials measure outcomes from 3 months to 1 year. Though the majority of cardiac arrest trials measure neurologic outcome using the Pittsburgh cerebral performance scale, while SAH trials utilize the Glasgow outcome scale or modified Rankin scale, all of these scales are very similar and provide gross estimates of disability. Despite the aforementioned methodological differences, certain interventions, such as magnesium and intensive insulin, have not proven effective in either population.

Another reason for variable outcome in clinical trials may be due to pathophysiological differences in SAH and cardiac arrest. Though early brain injury in SAH may mechanistically mirror the cascade of injury occurring after cardiac arrest, SAH differs from cardiac arrest in that it is not a monophasic disease. Break down of blood products initiates a distinctive series of delayed clinical events that characteristically can lead to ischemia or infarction between SAH days 3-14. The fact that nimodipine has been so successful in $\mathrm{SAH}$ trials, but shown no effect at similar doses in cardiac arrest trials suggests it is acting on a distinct pathway. Indeed, the absolute risk reduction for poor outcome after $\mathrm{SAH}$ in a meta-analysis of 16 trials of nimodipine is $5.3 \%$ with a number needed to treat for benefit of 19 [111]. No such signal for benefit was seen in cardiac arrest trials $[64,65$, 67]. The mechanism of beneficial effect of nimodipine in SAH has been widely debated and may be related to its effect on fibrinolysis [112], spreading cortical depression [113], or excitotoxicity. Though nimodipine improves ischemic neurological deficits by clinical criteria and CT-documented infarction (with a pooled relative risks of 0.66 (95\% CI $0.59-$ 0.75 ) and 0.78 (95\% CI $0.70-0.87)$, resp.) [111], it has little effect on angiographic vasospasm or cerebral blood flow $[4,5]$. The corollary to this observation is that interventions that improve angiographic vasospasm, such as clazosentan, do not necessarily improve cerebral infarction or outcome. $[49,50,114,115]$. While angiographic vasospasm seems to be related to infarction [116], other mechanisms may play a role in neurological deficits, cerebral infarction, and outcome. Such pathophysiological differences may make extrapolation of results from cardiac arrest trials to an SAH population problematic. Indeed, delayed cerebral ischemia (DCI) may blunt the positive effect of hypothermia on early brain injury. Further animal research may better identify mechanistic differences of early brain injury in cardiac arrest and SAH.

Despite a second wave of neurological injury in $\mathrm{SAH}$, poor-grade (Hunt Hess 4-5) SAH patients, who are at higher risk for secondary neurological injury, still have comparable, if not better, outcomes compared to cardiac arrest patients who are not cooled. Among Hunt-Hess grade 4-5 patients, the 12 -month mortality rate with aggressive treatment is $43 \%$, while $40 \%$ had no or slight-moderate disability (mRS 0-3) 
[117]. By comparison, the 6-month death rate in the control (nonhypothermia) group of the HACA trial was $55 \%$, while good neurologic outcome (defined as Pittsburgh cerebral performance scale 1-2; good outcome or moderate disability) occurred in $26-39 \%$ [88, 89]. We have additionally shown that DCI does not predict mortality after SAH with aggressive vasospasm treatment, while early brain injury (measured by Hunt-Hess grade) does [1]. Thus, despite secondary neurologic insults and delayed cerebral ischemia risk, poor-grade SAH patients do at least as well as normothermic cardiac arrest patients, who may face risks to survival and functional outcome related to the underlying cause of the cardiac arrest. Also, the median age of cardiac arrest patients tends to be older than SAH patients, which may also explain why even the sickest SAH patients have relatively good outcomes by comparison. If nihilism can be overcome in the management of poor-grade SAH patients, the early application of mild therapeutic hypothermia may improve outcomes further.

There are some limitations to this review that should be mentioned. A medical librarian was not used and only MEDLINE/PubMed and clinicaltrials.gov were used to identify literature for review. An Embase search was not performed. Additionally, an exhaustive search for all neurologic outcome based RCTs was not performed, rather only English studies in humans were included.

In conclusion, while the mechanisms of early brain injury after SAH and cardiac arrest may be similar, the preponderance of SAH clinical trials do not focus on interventions addressing early brain injury. Clinical trials in SAH assessing interventions that have proven successful in the cardiac arrest literature, such as early mild therapeutic hypothermia, are warranted.

\section{References}

[1] J. A. Frontera, A. Fernandez, J. M. Schmidt et al., "Defining vasospasm after subarachnoid hemorrhage: what is the most clinically relevant definition?" Stroke, vol. 40, no. 6, pp. 19631968, 2009.

[2] K. E. Wartenberg, J. M. Schmidt, J. Claassen et al., "Impact of medical complications on outcome after subarachnoid hemorrhage," Critical Care Medicine, vol. 34, no. 3, pp. 617-623, 2006.

[3] G. S. Allen, H. S. Ahn, T. J. Preziosi et al. et al., "Cerebral arterial spasm-a controlled trial of nimodipine in patients with subarachnoid hemorrhage," The New England Journal of Medicine, vol. 308, no. 11, pp. 619-624, 1983.

[4] K. C. Petruk, M. West, G. Mohr et al., "Nimodipine treatment in poor-grade aneurysm patients. Results of a multicenter doubleblind placebo-controlled trial," Journal of Neurosurgery, vol. 68, no. 4, pp. 505-517, 1988.

[5] E. Mee, D. Dorrance, D. Lowe, and G. Neil-Dwyer, "Controlled study of nimodipine in aneurysm patients treated early after subarachnoid hemorrhage," Neurosurgery, vol. 22, no. 3, pp. 484-491, 1988.

[6] J. D. Pickard, G. D. Murray, R. Illingworth et al., "Effect of oral nimodipine on cerebral infarction and outcome after subarachnoid haemorrhage: British aneurysm nimodipine trial," British Medical Journal, vol. 298, no. 6674, pp. 636-642, 1989.

[7] J. M. Gilsbach, H. J. Reulen, B. Ljunggren et al., "Early aneurysm surgery and preventive therapy with intravenously administered nimodipine: a multicenter, double-blind, dosecomparison study," Neurosurgery, vol. 26, no. 3, pp. 458-464, 1990.

[8] J. Ohman, A. Servo, and O. Heiskanen, "Long-term effects of nimodipine on cerebral infarcts and outcome after aneurysmal subarachnoid hemorrhage and surgery," Journal of Neurosurgery, vol. 74, no. 1, pp. 8-13, 1991.

[9] V. Soppi, P. N. Karamanakos, T. Koivisto et al., "A randomized outcome study of enteral versus intravenous nimodipine in 171 patients after acute aneurysmal subarachnoid hemorrhage," World Neurosurgery, vol. 78, no. 1-2, pp. 101-109, 2012.

[10] E. C. Haley Jr., N. F. Kassell, and J. C. Torner, "A randomized trial of nicardipine in subarachnoid hemorrhage: angiographic and transcranial Doppler ultrasound results. A report of the cooperative aneurysm study," Journal of Neurosurgery, vol. 78, no. 4, pp. 548-553, 1993.

[11] E. C. Haley Jr., N. F. Kassell, and J. C. Torner, "A randomized controlled trial of high-dose intravenous nicardipine in aneurysmal subarachnoid hemorrhage. A report of the cooperative aneurysm study," Journal of Neurosurgery, vol. 78, no. 4, pp. 537-547, 1993.

[12] E. C. Haley Jr., N. F. Kassell, J. C. Torner, L. L. Truskowski, and T. P. Germanson, "A randomized trial of two doses of nicardipine in aneurysmal subarachnoid hemorrhage: a report of the cooperative aneurysm study," Journal of Neurosurgery, vol. 80, no. 5, pp. 788-796, 1994.

[13] M. Barth, H. H. Capelle, S. Weidauer et al., "Effect of nicardipine prolonged-release implants on cerebral vasospasm and clinical outcome after severe aneurysmal subarachnoid hemorrhage: a prospective, randomized, double-blind phase IIa study," Stroke, vol. 38, no. 2, pp. 330-336, 2007.

[14] H. Fodstad, A. Forssell, B. Liliequist, and M. Schannong, "Antifibrinolysis with tranexamic acid in aneurysmal subarachnoid hemorrhage: a consecutive controlled clinical trial," Neurosurgery, vol. 8, no. 2, pp. 158-165, 1981.

[15] U. M. Chowdhary and K. Sayed, "Comparative clinical trial of epsilon amino-caproic acid and tranexamic acid in the prevention of early recurrence of subarachnoid haemorrhage," Journal of Neurology, Neurosurgery and Psychiatry, vol. 44, no. 9, pp. 810-813, 1981.

[16] M. Vermeulen, K. W. Lindsay, G. D. Murray et al. et al., "Antifibrinolytic treatment in subarachnoid hemorrhage," The New England Journal of Medicine, vol. 311, no. 7, pp. 432-437, 1984.

[17] Y. Roos, "Antifibrinolytic treatment in subarachnoid hemorrhage: a randomized placebo-controlled trial. STAR Study Group," Neurology, vol. 54, no. 1, pp. 77-82, 2000.

[18] J. Hillman, S. Fridriksson, O. Nilsson, Z. Yu, H. Säveland, and K. E. Jakobsson, "Immediate administration of tranexamic acid and reduced incidence of early rebleeding after aneurysmal subarachnoid hemorrhage: a prospective randomized study," Journal of Neurosurgery, vol. 97, no. 4, pp. 771-778, 2002.

[19] I. Saito, T. Asano, and C. Ochiai, "A double-blind clinical evaluation of the effect of nizofenone (Y-9179) on delayed ischemic neurological deficits following aneurysmal rupture," Neurological Research, vol. 5, no. 4, pp. 29-47, 1983.

[20] T. Ohta, H. Kikuchi, K. Hashi, and Y. Kudo, "Nizofenone administration in the acute stage following subarachnoid hemorrhage. Results of a multi-center controlled double-blind clinical study," Journal of Neurosurgery, vol. 64, no. 3, pp. 420-426, 1986.

[21] A. Munakata, H. Ohkuma, T. Nakano, N. Shimamura, K. Asano, and M. Naraoka, "Effect of a free radical scavenger, edaravone, 
in the treatment of patients with aneurysmal subarachnoid hemorrhage," Neurosurgery, vol. 64, no. 3, pp. 423-428, 2009.

[22] H. Yoneda, S. Shirao, J. Nakagawara, K. Ogasawara, T. Tominaga, and M. Suzuki, "A prospective, multicenter, randomized study of the efficacy of eicosapentaenoic acid for cerebral vasospasm: the EVAS study," World Neurosurgery, 2012.

[23] M. D. Hill, R. H. Martin, D. Mikulis et al. et al., "Safety and efficacy of NA-1 in patients with iatrogenic stroke after endovascular aneurysm repair (ENACT): a phase 2, randomised, doubleblind, placebo-controlled trial," The Lancet Neurology, vol. 11, no. 11, pp. 942-950, 2012.

[24] J. R. Lynch, H. Wang, M. J. McGirt et al., "Simvastatin reduces vasospasm after aneurysmal subarachnoid hemorrhage: results of a pilot randomized clinical trial," Stroke, vol. 36, no. 9, pp. 2024-2026, 2005.

[25] M. Y. Tseng, M. Czosnyka, H. Richards, J. D. Pickard, and P. J. Kirkpatrick, "Effects of acute treatment with pravastatin on cerebral vasospasm, autoregulation, and delayed ischemic deficits after aneurysmal subarachnoid hemorrhage: a phase II randomized placebo-controlled trial," Stroke, vol. 36, no. 8, pp. 1627-1632, 2005.

[26] S. H. Y. Chou, E. E. Smith, N. Badjatia et al., "A randomized, double-blind, placebo-controlled pilot study of simvastatin in aneurysmal subarachnoid hemorrhage," Stroke, vol. 39, no. 10, pp. 2891-2893, 2008.

[27] M. D. Vergouwen, J. C. Meijers, R. B. Geskus et al., "Biologic effects of simvastatin in patients with aneurysmal subarachnoid hemorrhage: a double-blind, placebo-controlled randomized trial," Journal of Cerebral Blood Flow and Metabolism, vol. 29, no. 8, pp. 1444-1453, 2009.

[28] J. Ohman and O. Heiskanen, "Timing of operation for ruptured supratentorial aneurysms: a prospective randomized study," Journal of Neurosurgery, vol. 70, no. 1, pp. 55-60, 1989.

[29] A. Molyneux, R. Kerr, I. Stratton et al., "International subarachnoid aneurysm trial (ISAT) of neurosurgical clipping versus endovascular coiling in 2143 patients with ruptured intracranial aneurysms: a randomised trial," The Lancet, vol. 360, no. 9342, pp. 1267-1274, 2002.

[30] A. J. Molyneux, R. S. Kerr, L. M. Yu et al., "International Subarachnoid Aneurysm Trial (ISAT) of neurosurgical clipping versus endovascular coiling in 2143 patients with ruptured intracranial aneurysms: a randomised comparison of effects on survival, dependency, seizures, rebleeding, subgroups, and aneurysm occlusion," The Lancet, vol. 366, no. 9488, pp. 809817, 2005.

[31] C. G. McDougall, R. F. Spetzler, J. M. Zabramski et al., "The barrow ruptured aneurysm trial," Journal of Neurosurgery, vol. 116, no. 1, pp. 135-144, 2012.

[32] N. F. Kassell, E. C. Haley Jr., C. Apperson-Hansen, and W. M. Alves, "Randomized, double-blind, vehicle-controlled trial of tirilazad mesylate in patients with aneurysmal subarachnoid hemorrhage: a cooperative study in Europe, Australia, and New Zealand," Journal of Neurosurgery, vol. 84, no. 2, pp. 221-228, 1996.

[33] E. C. Haley Jr., N. F. Kassell, C. Apperson-Hansen, M. H. Maile, and W. M. Alves, "A randomized, double-blind, vehiclecontrolled trial of tirilazad mesylate in patients with aneurysmal subarachnoid hemorrhage: a cooperative study in North America," Journal of Neurosurgery, vol. 86, no. 3, pp. 467-474, 1997.

[34] G. Lanzino, N. F. Kassell, N. W. C. Dorsch et al., "Doubleblind, randomized, vehicle-controlled study of high-dose tirilazad mesylate in women with aneurysmal subarachnoid hemorrhage-part I: a cooperative study in Europe, Australia, New Zealand, and South Africa," Journal of Neurosurgery, vol. 90, no. 6, pp. 1011-1017, 1999.

[35] G. Lanzino and N. F. Kassell, "Double-blind, randomized, vehicle-controlled study of high-dose tirilazad mesylate in women with aneurysmal subarachnoid hemorrhage-part II: a cooperative study in North America," Journal of Neurosurgery, vol. 90, no. 6, pp. 1018-1024, 1999.

[36] V. Seifert, D. Stolke, M. Zimmermann, and A. Feldges, "Prevention of delayed ischaemic deficits after aneurysmal subarachnoid haemorrhage by intrathecal bolus injection of tissue plasminogen activator (rTPA). A prospective study," Acta Neurochirurgica, vol. 128, no. 1-4, pp. 137-143, 1994.

[37] J. M. Findlay, "A randomized trial of intraoperative, intracisternal tissue plasminogen activator for the prevention of vasospasm," Neurosurgery, vol. 37, no. 5, pp. 1026-1027, 1995.

[38] T. Yamamoto, T. Esaki, Y. Nakao, and K. Mori, "Efficacy of lowdose tissue-plasminogen activator intracisternal administration for the prevention of cerebral vasospasm after subarachnoid hemorrhage," World Neurosurgery, vol. 73, no. 6, pp. 675-682, 2010.

[39] M. D. Shaw, P. M. Foy, M. Conway et al., "Dipyridamole and postoperative ischemic deficits in aneurysmal subarachnoid hemorrhage," Journal of Neurosurgery, vol. 63, no. 5, pp. 699703,1985 .

[40] W. M. van den Bergh, A. Algra, S. M. D. Mees, F. van Kooten, C. M. Dirven, J. van Gijn et al., "Randomized controlled trial of acetylsalicylic acid in aneurysmal subarachnoid hemorrhage: the MASH study," Stroke, vol. 37, no. 9, pp. 2326-2330, 2006.

[41] S. Suzuki, T. Sayama, T. Nakamura et al., "Cilostazol improves outcome after subarachnoid hemorrhage: a preliminary report," Cerebrovascular Diseases, vol. 32, no. 1, pp. 89-93, 2011.

[42] D. Hasan, K. W. Lindsay, E. F. M. Wijdicks et al., "Effect of fludrocortisone acetate in patients with subarachnoid hemorrhage," Stroke, vol. 20, no. 9, pp. 1156-1161, 1989.

[43] Y. Katayama, J. Haraoka, H. Hirabayashi et al., "A randomized controlled trial of hydrocortisone against hyponatremia in patients with aneurysmal subarachnoid hemorrhage," Stroke, vol. 38, no. 8, pp. 2373-2375, 2007.

[44] P. Gomis, J. P. Graftieaux, R. Sercombe, D. Hettler, B. Scherpereel, and P. Rousseaux, "Randomized, double-blind, placebo-controlled, pilot trial of high-dose methylprednisolone in aneurysmal subarachnoid hemorrhage," Journal of Neurosurgery, vol. 112, no. 3, pp. 681-688, 2010.

[45] M. Y. Tseng, P. J. Hutchinson, H. K. Richards et al., "Acute systemic erythropoietin therapy to reduce delayed ischemic deficits following aneurysmal subarachnoid hemorrhage: a phase II randomized, double-blind, placebo-controlled trial: clinical article," Journal of Neurosurgery, vol. 111, no. 1, pp. 171180, 2009.

[46] A. M. Naidech, A. Shaibani, R. K. Garg et al., "Prospective, randomized trial of higher goal hemoglobin after subarachnoid hemorrhage," Neurocritical Care, vol. 13, no. 3, pp. 313-320, 2010.

[47] J. I. Suarez, R. H. Martin, E. Calvillo et al. et al., "The albumin in subarachnoid hemorrhage (ALISAH) multicenter pilot clinical trial: safety and neurologic outcomes," Stroke, vol. 43, no. 3, pp. 683-690, 2012.

[48] B. A. Bell, "Effect of calcitonin-gene-related peptide in patients with delayed postoperative cerebral ischaemia after aneurysmal subarachnoid haemorrhage," The Lancet, vol. 339, no. 8797, pp. 831-834, 1992. 
[49] R. L. Macdonald, R. T. Higashida, E. Keller et al., "Clazosentan, an endothelin receptor antagonist, in patients with aneurysmal subarachnoid haemorrhage undergoing surgical clipping: a randomised, double-blind, placebo-controlled phase 3 trial (CONSCIOUS-2)," The Lancet Neurology, vol. 10, no. 7, pp. 618625, 2011.

[50] R. L. Macdonald, R. T. Higashida, E. Keller et al. et al., "Randomized trial of clazosentan in patients with aneurysmal subarachnoid hemorrhage undergoing endovascular coiling," Stroke, vol. 43, no. 6, pp. 1463-1469, 2012.

[51] L. Lennihan, S. A. Mayer, M. E. Fink et al., "Effect of hypervolemic therapy on cerebral blood flow after subarachnoid hemorrhage: a randomized controlled trial," Stroke, vol. 31, no. 2, pp. 383-391, 2000.

[52] A. Egge, K. Waterloo, H. Sjøholm, T. Solberg, T. Ingebrigtsen, and B. Romner, "Prophylactic hyperdynamic postoperative fluid therapy after aneurysmal subarachnoid hemorrhage: a clinical, prospective, randomized, controlled study," Neurosurgery, vol. 49, no. 3, pp. 593-606, 2001.

[53] G. K. C. Wong, W. S. Poon, M. T. V. Chan et al., "Intravenous magnesium sulphate for aneurysmal subarachnoid hemorrhage (IMASH): a randomized, double-blinded, placebo-controlled, multicenter phase III trial," Stroke, vol. 41, no. 5, pp. 921-926, 2010.

[54] S. M. D. Mees, A. Algra, W. P. Vandertop et al. et al., "Magnesium for aneurysmal subarachnoid haemorrhage (MASH-2): a randomised placebo-controlled trial," The Lancet, vol. 380, no. 9836, pp. 44-49, 2012.

[55] P. Walter, G. Neil-Dwyer, and J. M. Cruickshank, "Beneficial effects of adrenergic blockade in patients with subarachnoid haemorrhage," The British Medical Journal, vol. 284, no. 6330, pp. 1661-1664, 1982.

[56] M. Zwienenberg-Lee, J. Hartman, N. Rudisill et al., "Effect of prophylactic transluminal balloon angioplasty on cerebral vasospasm and outcome in patients with fisher grade IIi subarachnoid hemorrhage: results of a phase II multicenter, randomized, clinical trial," Stroke, vol. 39, no. 6, pp. 1759-1765, 2008.

[57] M. Shibuya, Y. Suzuki, K. Sugita et al., "Effect of AT877 on cerebral vasospasm after aneurysmal subarachnoid hemorrhage: results of a prospective placebo-controlled double-blind trial," Journal of Neurosurgery, vol. 76, no. 4, pp. 571-577, 1992.

[58] J. Zhao, D. Zhou, J. Guo et al. et al., "Efficacy and safety of fasudil in patients with subarachnoid hemorrhage: final results of a randomized trial of fasudil versus nimodipine," Neurologia Medico-Chirurgica, vol. 51, no. 10, pp. 679-683, 2011.

[59] F. Bilotta, A. Spinelli, F. Giovannini, A. Doronzio, R. Delfini, and G. Rosa, "The effect of intensive insulin therapy on infection rate, vasospasm, neurologic outcome, and mortality in neurointensive care unit after intracranial aneurysm clipping in patients with acute subarachnoid hemorrhage: a randomized prospective pilot trial," Journal of Neurosurgical Anesthesiology, vol. 19, no. 3, pp. 156-160, 2007.

[60] M. M. Todd, B. J. Hindman, W. R. Clarke, and J. C. Torner, "Mild intraoperative hypothermia during surgery for intracranial aneurysm," The New England Journal of Medicine, vol. 352, no. 2, pp. 135-145, 2005.

[61] E. Grote and W. Hassler, "The critical first minutes after subarachnoid hemorrhage," Neurosurgery, vol. 22, no. 4, pp. 654-661, 1988.

[62] F. A. Sehba, G. Mostafa, V. Friedrich Jr., and J. B. Bederson, "Acute microvascular platelet aggregation after subarachnoid hemorrhage," Journal of Neurosurgery, vol. 102, no. 6, pp. 1094$1100,2005$.

[63] F. A. Sehba and J. B. Bederson, "Mechanisms of acute brain injury after subarachnoid hemorrhage," Neurological Research, vol. 28, no. 4, pp. 381-398, 2006.

[64] M. Forsman, H. P. Aarseth, H. K. Nordby, A. Skulberg, and P. A. Steen, "Effects of nimodipine on cerebral blood flow and cerebrospinal fluid pressure after cardiac arrest: correlation with neurologic outcome," Anesthesia and Analgesia, vol. 68, no. 4, pp. 436-443, 1989.

[65] R. O. Roine, S. Kajaste, and M. Kaste, "Neuropsychological sequelae of cardiac arrest," The Journal of the American Medical Association, vol. 269, no. 2, pp. 237-242, 1992.

[66] Brain Resuscitation Clinical Trial II Study Group, "A randomized clinical study of a calcium-entry blocker (lidoflazine) in the treatment of comatose survivors of cardiac arrest," The New England Journal of Medicine, vol. 324, no. 18, pp. 1225-1231, 1991.

[67] R. O. Roine, M. Kaste, A. Kinnunen, P. Nikki, S. Sarna, and S. Kajaste, "Nimodipine after resuscitation from out-ofhospital ventricular fibrillation. A placebo-controlled, doubleblind, randomized trial," The Journal of the American Medical Association, vol. 264, no. 24, pp. 3171-3177, 1990.

[68] M. S. Damian, D. Ellenberg, R. Gildemeister et al., "Coenzyme Q10 combined with mild hypothermia after cardiac arrest: a preliminary study," Circulation, vol. 110, no. 19, pp. 3011-3016, 2004.

[69] D. M. Fatovich, G. J. Dobb, and R. A. Clugston, "A pilot randomised trial of thrombolysis in cardiac arrest (the TICA trial)," Resuscitation, vol. 61, no. 3, pp. 309-313, 2004.

[70] B. W. Böttiger, H. R. Arntz, D. A. Chamberlain et al., "Thrombolysis during resuscitation for out-of-hospital cardiac arrest," The New England Journal of Medicine, vol. 359, no. 25, pp. 26512662, 2008.

[71] S. D. Mentzelopoulos, S. G. Zakynthinos, M. Tzoufi et al., "Vasopressin, epinephrine, and corticosteroids for in-hospital cardiac arrest," Archives of Internal Medicine, vol. 169, no. 1, pp. 15-24, 2009.

[72] C. G. Brown, D. R. Martin, P. E. Pepe et al. et al., "A comparison of standard-dose and high-dose epinephrine in cardiac arrest outside the hospital. The multicenter high-dose epinephrine study group," The New England Journal of Medicine, vol. 327, no. 15, pp. 1051-1055, 1992.

[73] C. Choux, P. Y. Gueugniaud, A. Barbieux et al., "Standard doses versus repeated high doses of epinephrine in cardiac arrest outside the hospital," Resuscitation, vol. 29, no. 1, pp. 3-9, 1995.

[74] W. D. Patrick, J. Freedman, T. McEwen, R. B. Light, L. Ludwig, and D. Roberts, "A randomized, double-blind comparison of methoxamine and epinephrine in human cardiopulmonary arrest," The American Journal of Respiratory and Critical Care Medicine, vol. 152, no. 2, pp. 519-523, 1995.

[75] K. H. Lindner, B. Dirks, H. U. Strohmenger, A. W. Prengel, I. M. Lindner, and K. G. Lurie, "Randomised comparison of epinephrine and vasopressin in patients with out-of-hospital ventricular fibrillation," The Lancet, vol. 349, no. 9051, pp. 535537, 1997.

[76] B. W. Sherman, M. A. Munger, G. E. Foulke, W. F. Rutherford, and E. A. Panacek, "High-dose versus standard-dose epinephrine treatment of cardiac arrest after failure of standard therapy," Pharmacotherapy, vol. 17, no. 2, pp. 242-247, 1997.

[77] P. Y. Gueugniaud, P. Mols, P. Goldstein et al., "A comparison of repeated high doses and repeated standard doses of epinephrine 
for cardiac arrest outside the hospital," The New England Journal of Medicine, vol. 339, no. 22, pp. 1595-1601, 1998.

[78] I. G. Stiell, P. C. Hébert, G. A. Wells et al., "Vasopressin versus epinephrine for inhospital cardiac arrest: a randomised controlled trial," The Lancet, vol. 358, no. 9276, pp. 105-109, 2001.

[79] V. Wenzel, A. C. Krismer, H. R. Arntz, H. Sitter, K. H. Stadlbauer, and K. H. Lindner, "A comparison of vasopressin and epinephrine for out-of-hospital cardiopulmonary resuscitation," The New England Journal of Medicine, vol. 350, no. 2, pp. 105-113, 2004.

[80] P. Y. Gueugniaud, J. S. David, E. Chanzy et al. et al., "Vasopressin and epinephrine vs. epinephrine alone in cardiopulmonary resuscitation," The New England Journal of Medicine, vol. 359, no. 1, pp. 21-30, 2008.

[81] M. C. Thel, A. L. Armstrong, S. E. McNulty, R. M. Califf, and C. M. O'Connor, "Randomised trial of magnesium in in-hospital cardiac arrest," The Lancet, vol. 350, no. 9087, pp. 1272-1276, 1997.

[82] D. M. Fatovich, D. A. Prentice, and G. J. Dobb, "Magnesium in cardiac arrest (the magic trial)," Resuscitation, vol. 35, no. 3, pp. 237-241, 1997.

[83] J. Allegra, R. Lavery, R. Cody et al., "Magnesium sulfate in the treatment of refractory ventricular fibrillation in the prehospital setting," Resuscitation, vol. 49, no. 3, pp. 245-249, 2001.

[84] T. B. Hassan, C. Jagger, and D. B. Barnett, "A randomised trial to investigate the efficacy of magnesium sulphate for refractory ventricular fibrillation," Emergency Medicine Journal, vol. 19, no. 1, pp. 57-62, 2002.

[85] W. T. Longstreth Jr., C. E. Fahrenbruch, M. Olsufka, T. R. Walsh, M. K. Copass, and L. A. Cobb, "Randomized clinical trial of magnesium, diazepam, or both after out-of-hospital cardiac arrest," Neurology, vol. 59, no. 4, pp. 506-514, 2002.

[86] W. T. Longstreth Jr., M. K. Copass, L. K. Dennis, M. E. RauchMatthews, M. S. Stark, and L. A. Cobb, "Intravenous glucose after out-of-hospital cardiopulmonary arrest: a communitybased randomized trial," Neurology, vol. 43, no. 12 I, pp. 25342541, 1993.

[87] T. Oksanen, M. B. Skrifvars, T. Varpula et al., "Strict versus moderate glucose control after resuscitation from ventricular fibrillation," Intensive Care Medicine, vol. 33, no. 12, pp. 20932100, 2007.

[88] S. A. Bernard, T. W. Gray, M. D. Buist et al., "Treatment of comatose survivors of out-of-hospital cardiac arrest with induced hypothermia," The New England Journal of Medicine, vol. 346, no. 8, pp. 557-563, 2002.

[89] The Hypothermia after Cardiac Arrest Study Group, "Mild therapeutic hypothermia to improvethe neurologic outcome after cardiac arrest," The New England Journal of Medicine, vol. 346, no. 8, pp. 549-556, 2002.

[90] F. Kim, M. Olsufka, W. T. Longstreth Jr. et al., "Pilot randomized clinical trial of prehospital induction of mild hypothermia in out-of-hospital cardiac arrest patients with a rapid infusion of $4{ }^{\circ} \mathrm{C}$ normal saline," Circulation, vol. 115, no. 24, pp. 3064-3070, 2007.

[91] A. Kämäräinen, I. Virkkunen, J. Tenhunen, A. Yli-Hankala, and T. Silfvast, "Prehospital therapeutic hypothermia for comatose survivors of cardiac arrest: a randomized controlled trial," Acta Anaesthesiologica Scandinavica, vol. 53, no. 7, pp. 900-907, 2009.

[92] M. Castrén, P. Nordberg, L. Svensson et al., "Intra-arrest transnasal evaporative cooling: a randomized, prehospital, multicenter study (PRINCE: pre-ROSCintraNasal cooling effectiveness)," Circulation, vol. 122, no. 7, pp. 729-736, 2010.
[93] T. J. Cohen, B. G. Goldner, P. C. Maccaro et al., "A comparison of active compression-decompression cardiopulmonary resuscitation with standard cardiopulmonary resuscitation for cardiac arrests occurring in the hospital," The New England Journal of Medicine, vol. 329, no. 26, pp. 1918-1921, 1993.

[94] I. G. Stiell, P. C. Hébert, G. A. Wells et al., “The Ontario trial of active compression-decompression cardiopulmonary resuscitation for in-hospital and prehospital cardiac arrest," The Journal of the American Medical Association, vol. 275, no. 18, pp. 1417-1423, 1996.

[95] A. Hallstrom, L. Cobb, E. Johnson, and M. Copass, "Cardiopulmonary resuscitation by chest compression alone or with mouth-to-mouth ventilation," The New England Journal of Medicine, vol. 342, no. 21, pp. 1546-1553, 2000.

[96] C. Bertrand, F. Hemery, P. Carli et al., "Constant flow insufflation of oxygen as the sole mode of ventilation during out-ofhospital cardiac arrest," Intensive Care Medicine, vol. 32, no. 6, pp. 843-851, 2006.

[97] L. Svensson, K. Bohm, M. Castrèn et al., "Compression-only CPR or standard CPR in out-of-hospital cardiac arrest," The New England Journal of Medicine, vol. 363, no. 5, pp. 434-442, 2010.

[98] T. D. Rea, C. Fahrenbruch, L. Culley et al., "CPR with chest compression alone or with rescue breathing," The New England Journal of Medicine, vol. 363, no. 5, pp. 423-433, 2010.

[99] T. P. Aufderheide, G. Nichol, T. D. Rea et al. et al., "A trial of an impedance threshold device in out-of-hospital cardiac arrest," The New England Journal of Medicine, vol. 365, no. 9, pp. 798806, 2011.

[100] R. B. Abu-Laban, C. M. McIntyre, J. M. Christenson et al., "Aminophylline in bradyasystolic cardiac arrest: a randomised placebo-controlled trial," The Lancet, vol. 367, no. 9522, pp. 1577-1584, 2006.

[101] B. E. Heradstveit, A. B. Guttormsen, J. Langorgen et al. et al., "Capillary leakage in post-cardiac arrest survivors during therapeutic hypothermia-a prospective, randomised study," Scandinavian Journal of Trauma, Resuscitation and Emergency Medicine, vol. 18, article 29, 2010.

[102] Brain Resuscitation Clinical Trial I Study Group, "Randomized clinical study of thiopental loading in comatose survivors of cardiac arrest," The New England Journal of Medicine, vol. 314, no. 7, pp. 397-403, 1986.

[103] H. A. Stueven, B. M. Thompson, C. Aprahamian, and D. J. Tonsfeldt, "Calcium chloride: reassessment of use in asystole," Annals of Emergency Medicine, vol. 13, no. 9, pp. 820-822, 1984.

[104] H. A. Stueven, B. Thompson, C. Aprahamian, D. J. Tonsfeldt, and E. H. Kastenson, "The effectiveness of calcium chloride in refractory electromechanical dissociation," Annals of Emergency Medicine, vol. 14, no. 7, pp. 626-629, 1985.

[105] H. A. Stueven, B. Thompson, C. Aprahamian, D. J. Tonsfeldt, and E. H. Kastenson, "Lack of effectiveness of calcium chloride in refractory asystole," Annals of Emergency Medicine, vol. 14, no. 7, pp. 630-632, 1985.

[106] T. Dybvik, T. Strand, and P. A. Steen, "Buffer therapy during outof-hospital cardiopulmonary resuscitation," Resuscitation, vol. 29, no. 2, pp. 89-95, 1995.

[107] R. B. Vukmir and L. Katz, "Sodium bicarbonate improves outcome in prolonged prehospital cardiac arrest," American Journal of Emergency Medicine, vol. 24, no. 2, pp. 156-161, 2006. 
[108] I. Laurent, C. Adrie, C. Vinsonneau et al., "High-volume hemofiltration after out-of-hospital cardiac arrest: a randomized study," Journal of the American College of Cardiology, vol. 46, no. 3, pp. 432-437, 2005.

[109] I. G. Stiell, G. Nichol, B. G. Leroux et al. et al., "Early versus later rhythm analysis in patients with out-of-hospital cardiac arrest," The New England Journal of Medicine, vol. 365, no. 9, pp. 787797, 2011.

[110] G. S. Allen, H. S. Ahn, T. J. Preziosi et al. et al., "Cerebral arterial spasm: a controlled trial of nimodipine in patients with subarachnoid hemorrhage," The New England Journal of Medicine, vol. 308, no. 11, pp. 619-624, 1983.

[111] S. M. D. Mees, G. J. E. Rinkel, V. L. Feigin et al., "Calcium antagonists for aneurysmal subarachnoid hemorrhage," Stroke, vol. 39, no. 2, pp. 514-515, 2008.

[112] Y. B. W. E. M. Roos, M. Levi, T. A. Carroll, L. F. M. Beenen, and M. Vermeulen, "Nimodipine increases fibrinolytic activity in patients with aneurysmal subarachnoid hemorrhage," Stroke, vol. 32, no. 8, pp. 1860-1862, 2001.

[113] J. P. Dreier, K. Körner, N. Ebert et al., "Nitric oxide scavenging by hemoglobin or nitric oxide synthase inhibition by $N$-nitro$\mathrm{L}$-arginine induces cortical spreading ischemia when $\mathrm{K}^{+}$is increased in the subarachnoid space," Journal of Cerebral Blood Flow and Metabolism, vol. 18, no. 9, pp. 978-990, 1998.

[114] M. D. Vergouwen, A. Algra, and G. J. Rinkel, "Endothelin receptor antagonists for aneurysmal subarachnoid hemorrhage: a systematic review and meta-analysis update," Stroke, vol. 43, no. 10, pp. 2671-2676, 2012.

[115] X. Wang, Y. M. Li, W. Q. Li, C. G. Huang, Y. C. Lu, and L. J. Hou, "Effect of clazosentan in patients with aneurysmal subarachnoid hemorrhage: a meta-analysis of randomized controlled trials," PloS ONE, vol. 7, no. 10, Article ID e47778, 2012.

[116] R. W. Crowley, R. Medel, A. S. Dumont et al. et al., "Angiographic vasospasm is strongly correlated with cerebral infarction after subarachnoid hemorrhage," Stroke, vol. 42, no. 4, pp. 919-923, 2011.

[117] J. Mocco, E. R. Ransom, R. J. Komotar et al., "Preoperative prediction of long-term outcome in poor-grade aneurysmal subarachnoid hemorrhage," Neurosurgery, vol. 59, no. 3, pp. 529-538, 2006. 


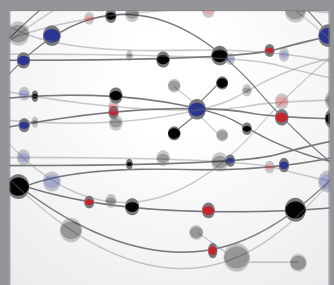

The Scientific World Journal
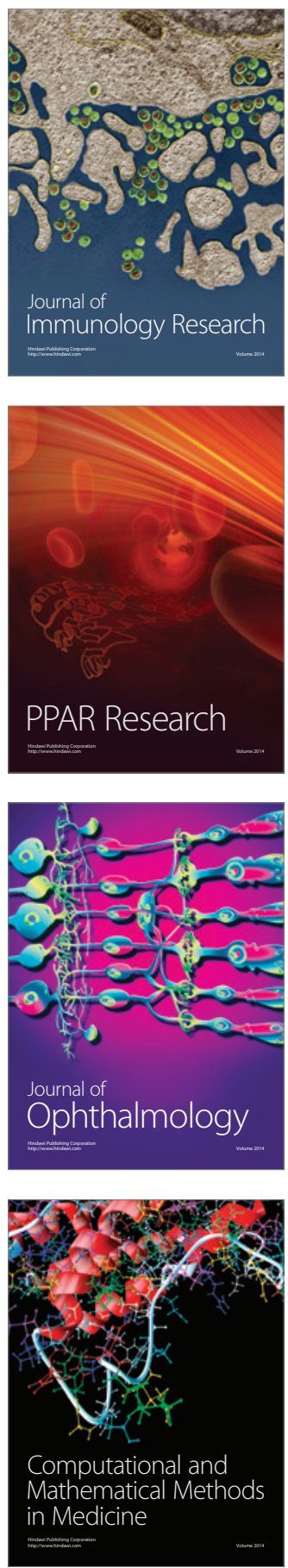

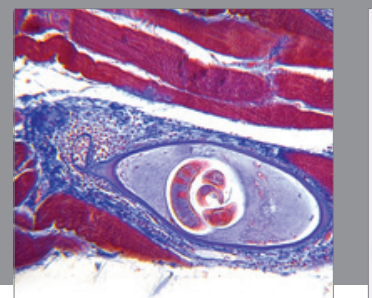

Gastroenterology

Research and Practice
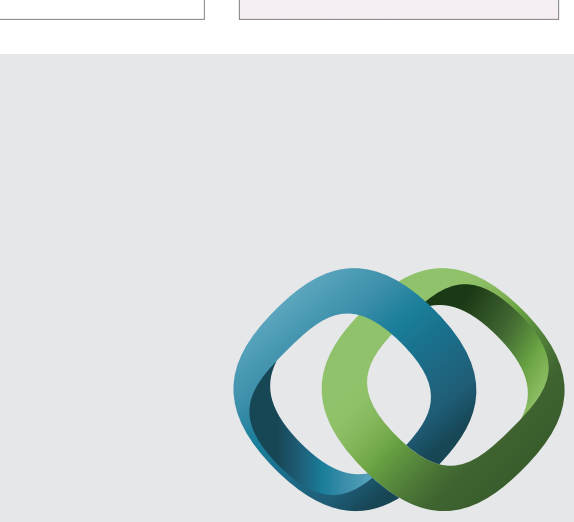

\section{Hindawi}

Submit your manuscripts at

http://www.hindawi.com
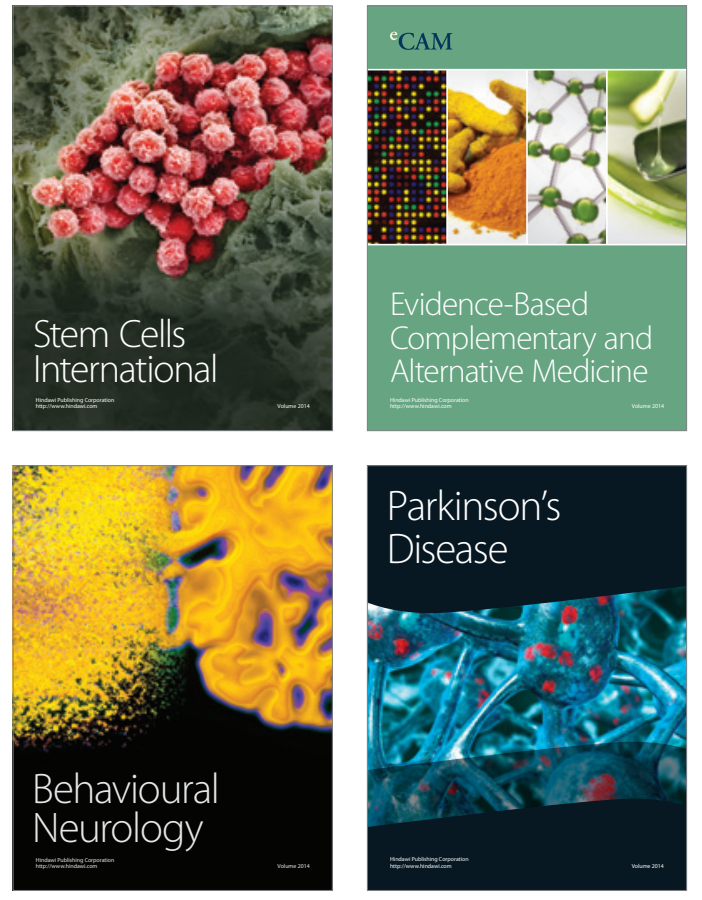
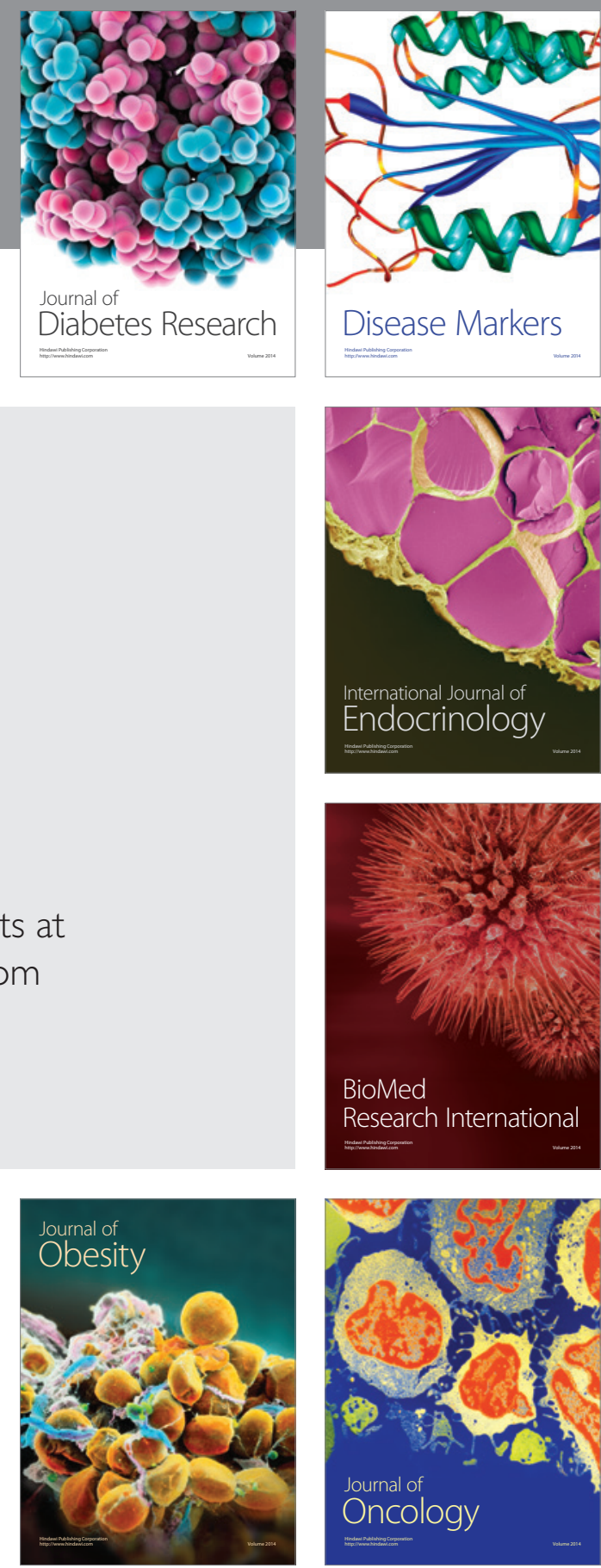

Disease Markers
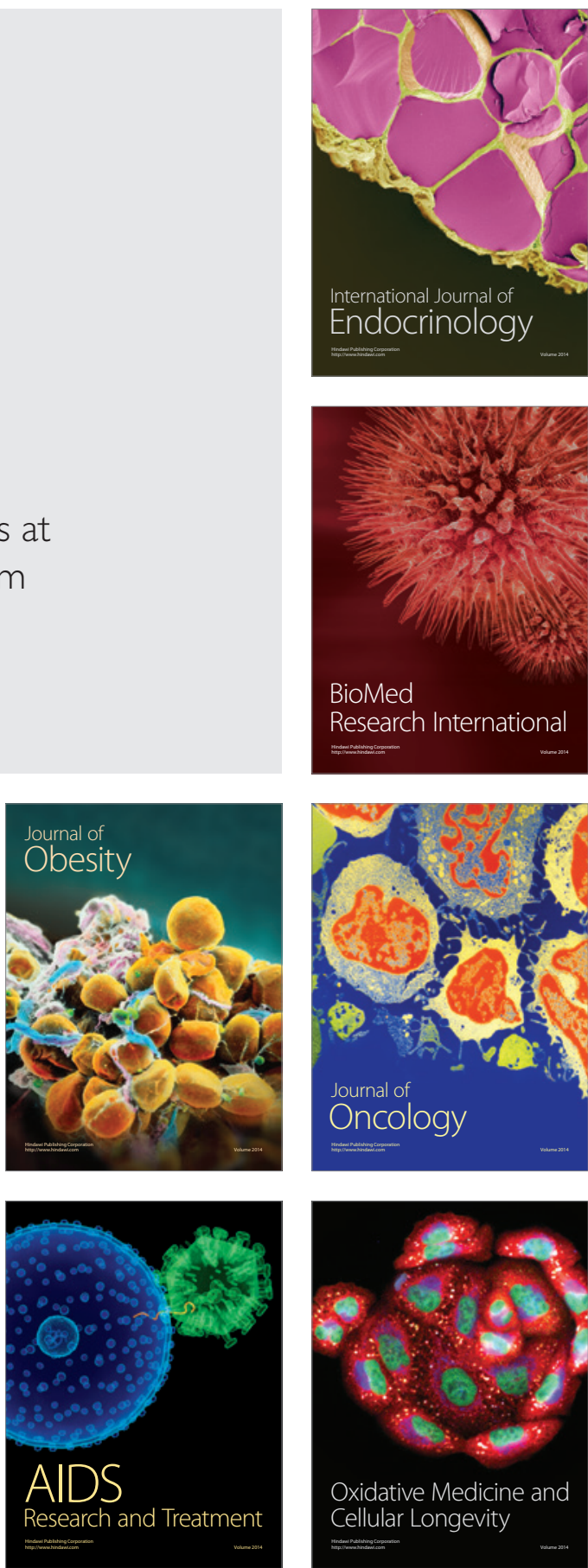